\title{
Cytokines and Chemokines in Cerebral Malaria Pathogenesis
}

\author{
Josefine Dunst ${ }^{1,2,3 *}$, Faustin Kamena ${ }^{1,2,3}$ and Kai Matuschewski ${ }^{1,2}$ \\ ${ }^{1}$ Parasitology Unit, Max Planck Institute for Infection Biology, Berlin, Germany, ${ }^{2}$ Institute of Chemistry and Biochemistry, Free \\ University, Berlin, Germany, ${ }^{3}$ Molecular Parasitology, Institute of Biology, Humboldt University, Berlin, Germany
}

Cerebral malaria is among the major causes of malaria-associated mortality and effective adjunctive therapeutic strategies are currently lacking. Central pathophysiological processes involved in the development of cerebral malaria include an imbalance of pro- and anti-inflammatory responses to Plasmodium infection, endothelial cell activation, and loss of blood-brain barrier integrity. However, the sequence of events, which initiates these pathophysiological processes as well as the contribution of their complex interplay to the development of cerebral malaria remain incompletely understood. Several cytokines and chemokines have repeatedly been associated with cerebral malaria severity. Increased levels of these inflammatory mediators could account for the sequestration of leukocytes in the cerebral microvasculature present during cerebral malaria, thereby contributing to an amplification of local inflammation and promoting cerebral malaria pathogenesis. Herein, we highlight the current knowledge on the contribution of cytokines and chemokines to the pathogenesis of cerebral malaria with particular emphasis on their roles in endothelial activation and leukocyte recruitment, as well as their implication in the progression to blood-brain barrier permeability and neuroinflammation, in both human cerebral malaria and in the murine experimental

OPEN ACCESS

Edited by:

Slobodan Paessler,

University of Texas Medical Branch,

United States

Reviewed by:

Tracey Lamb,

University of Utah, United States

Teresa Carvalho,

La Trobe University, Australia

*Correspondence:

Josefine Dunst

dunstj@zedat.fu-berlin.de

Received: 23 February 2017 Accepted: 03 July 2017

Published: 20 July 2017

Citation:

Dunst J, Kamena F and Matuschewski K (2017) Cytokines and Chemokines in Cerebral Malaria Pathogenesis.

Front. Cell. Infect. Microbiol. 7:324.

doi: 10.3389/fcimb.2017.00324 cerebral malaria model. A better molecular understanding of these processes could provide the basis for evidence-based development of adjunct therapies and the definition of diagnostic markers of disease progression.

Keywords: malaria, Plasmodium, cerebral malaria, cytokines, chemokines, endothelial activation, blood-brain barrier, neuroinflammation

\section{INTRODUCTION}

Malaria is one of the most prevalent infectious diseases worldwide and contributes considerably to the global disease burden. With $\sim 200$ million new cases and an estimated 430,000 deaths annually (WHO, 2016), malaria remains the most important vector-borne infectious disease. The human-adapted Plasmodium species $P$. falciparum and $P$. vivax account for the majority of malaria cases and are transmitted by the bite of an infective Anopheles mosquito. Despite considerable progress in malaria eradication over the past 15 years (WHO, 2016),

Abbreviations: CD, cluster of differentiation; CM, cerebral malaria; CSF, cerebrospinal fluid; DAMP, danger-associated molecular patterns; DC, dendritic cell; ECM, experimental cerebral malaria; EPCR, endothelial protein C receptor; GPI, glycosylphosphatidylinositol; ICAM, intercellular adhesion molecule; IFN, interferon; IL, interleukin; IP-10, IFN- $\gamma$-inducible protein 10; KC, keratinocyte chemoattractant; LPS, lipopolysaccharide; LT, lymphotoxin; MCP-1, monocyte chemoattractant protein 1; MIG, monokine induced by IFN- $\gamma$; MIP, macrophage inflammatory protein; NK, natural killer; NLR, NOD-like receptors, PAMP, pathogen-associated molecular pattern; PF4, platelet factor 4; PfEMP1, Plasmodium falciparum erythrocyte membrane protein 1; PRR, pattern recognition receptor; TLR, Toll-like receptor; TNF, tumor necrosis factor; VCAM, vascular cell adhesion molecule; ZO-1, zonula occludens 1. 
efforts are hampered by emerging Plasmodium resistance to commonly used anti-malaria drugs (Cui et al., 2015) and limited efficacy of the currently most advanced vaccine candidate (White et al., 2015; Olotu et al., 2016).

Among infections by human host-adapted Plasmodium species, $P$. falciparum infections are most likely to progress to organ-related pathology and severe malaria, and thereby account for the vast majority of malaria-associated fatalities. Along with severe anemia and respiratory distress, cerebral malaria (CM) is one of the major manifestations of severe malaria (Haldar et al., 2007). CM manifests with impaired consciousness and coma in both children and adults (Idro et al., 2010), while other clinical features differ. In addition to the characteristic diffuse encephalopathy, retinal abnormalities are frequent in children and less common in adults with CM (Beare et al., 2006; Idro et al., 2010). In contrast, CM in adults is accompanied by multiorgan disorder including renal failure and pulmonary edema, which are less frequently observed in children suffering from CM (Idro et al., 2010). Although anti-malaria treatment using artesunate was reported to improve CM outcome in children and adults (Dondorp et al., 2005, 2010), the case-fatality rate of pediatric CM is approximately 20\% (Haldar et al., 2007) and sustained cognitive and/or neurological impairment may occur (John et al., 2008a). Consequently, treatment strategies, which not only target the parasite but also other mechanisms underlying CM pathogenesis, need to be developed. Since the pathogenesis of CM is still incompletely understood, further investigations are an important medical research priority, especially in the context of adjunctive therapies. Since accumulating evidence indicates that an imbalance in pro- and anti-inflammatory immune responses partially contributes to $\mathrm{CM}$ pathogenesis, such therapeutic approaches could target cytokines and chemokines associated with CM severity. Cytokines are polypeptides, which mediate and generate inflammatory responses. Along with their contribution to disease pathogenesis in general, cytokines also exert physiological roles at lower concentrations (Clark and Vissel, 2017). Chemokines are chemotactic cytokines, which recruit lymphocytes and monocytes to the site of pathogen encounter by binding to their respective chemokine receptor (Griffith et al., 2014). Given that leukocytes were found to sequester in the microvasculature of the brain in human $\mathrm{CM}$ and murine ECM (Hunt and Grau, 2003), local chemokine gradients may mediate leukocyte recruitment and thus promote CM pathogenesis. Chemokines exert their function through binding to their respective $G$ protein-coupled chemokine receptors (Table 1), which induces activation of phosphatidylinositol 3kinase (PI3K) and Rho GTPase signaling pathways, thus leading to $\mathrm{F}$-actin polymerization and migration (Viola and Luster, 2008).

In this review, we highlight findings from both experimental murine models and natural human infections, and assess the current knowledge on the role of host cytokine and chemokine responses in the severe malaria complication of cerebral malaria. We also emphasize the potential inflammatory cascade resulting from Plasmodium life cycle progression after sporozoite inoculation and ultimately culminating in cerebral malaria pathology (Figure 1).

\section{CURRENT CONCEPTS IN CEREBRAL MALARIA PATHOGENESIS}

Two central concepts to explain CM pathogenesis have evolved and they are likely mutually dependent- the vascular occlusion hypothesis and the inflammation hypothesis (Storm and Craig, 2014).

The concept of vascular occlusion leading to CM is based on the ability of mature $P$. falciparum-infected erythrocytes to sequester in the microvasculature through binding of P. falciparum erythrocyte membrane protein 1 (PfEMP1) present on the erythrocyte surface to endothelial cell surface proteins, such as intercellular adhesion molecule 1 (ICAM1 ), vascular cell adhesion molecule 1 (VCAM-1), cluster of differentiation 36 (CD36), or endothelial protein $\mathrm{C}$ receptor (EPCR) (Pasloske and Howard, 1994; Chen et al., 2000; Rowe et al., 2009; Smith et al., 2013; Turner et al., 2013; Lennartz et al., 2017). Sequestration occurs in various organs and, along with increased rigidity of erythrocytes, is believed to cause vascular occlusion (Dondorp et al., 2004). Additionally, microvascular obstruction during $P$. falciparum infection may be worsened by the formation of rosettes and clumps (Chen et al., 2000; Rowe et al., 2009; Adams et al., 2014), i.e., the binding of uninfected erythrocytes by infected erythrocytes (Handunnetti et al., 1989), and aggregation of infected erythrocytes and platelets (Pain et al., 2001), respectively. These events may cause a reduction in microvascular blood flow, ischemia, and tissue hypoxia (Medana and Turner, 2006), thereby accounting for cerebral pathology. Reduced vessel perfusion and occlusion was indeed observed by fluorescein angiography of the retina in pediatric CM cases (Beare et al., 2009) and by in vivo imaging of the microcirculation in adult patients with $\mathrm{CM}$ or other manifestations of severe malaria (Dondorp et al., 2008), although further studies are needed to determine the underlying cause of these observations. Additionally, sequestration of $P$. falciparum-infected erythrocytes was observed in the cerebral microvasculature of CM patients in post mortem brain histology studies (Ponsford et al., 2012; Milner et al., 2014, 2015).

Despite accumulating evidence, the relevance of sequestration in the development of CM is still incompletely understood, since the degree of sequestration in brains of non-fatal CM cases cannot be investigated non-invasively and is, thus, unspecified (Miller et al., 2002). Occasionally, fatal CM cases present little sequestration and vessel occlusion similar to non-CM severe malaria cases (Ponsford et al., 2012). Moreover, isolated CM cases were reported in children and adults with confirmed $P$. vivax mono-infections in India (Kochar et al., 2009), although $P$. vivax is unlikely to sequester in the microvasculature since late-stage $P$. vivax-infected erythrocytes are present in peripheral blood (Anstey et al., 2009). Together, cerebral malaria occasionally develops in a few $P$. vivax infections without obvious signs of sequestration in vivo or microvascular obstruction.

Given the unresolved role of sequestration in the pathogenesis of CM, additional factors may determine disease severity. Notably, other infectious diseases that result in systemic inflammation and fever also progress to severe forms, 
TABLE 1 | Selected human and murine chemokines and their receptors ${ }^{a}$.

\begin{tabular}{|c|c|c|c|c|c|}
\hline \multirow[t]{2}{*}{ Chemokine } & \multirow[t]{2}{*}{ Other names } & \multicolumn{2}{|c|}{ Gene } & \multirow[t]{2}{*}{ Receptors } & \multirow[t]{2}{*}{ Key function } \\
\hline & & Human & Mouse & & \\
\hline CCL2 & $\begin{array}{l}\text { MCP-1 } \\
\text { JE (mouse) }\end{array}$ & CCL2 & Ccl2 & CCR2 & Inflammatory monocyte trafficking \\
\hline CCL3 & $\mathrm{MIP}-1 \alpha$ & CCL3 & $\mathrm{Ccl3}$ & CCR1, CCR5 & Macrophage and NK cell migration, T cell-DC interactions \\
\hline CCL4 & MIP-1 $\beta$ & CCL4 & $\mathrm{Ccl} 4$ & CCR5 & \\
\hline CCL5 & RANTES & CCL5 & Ccl5 & CCR1, CCR3, CCR5 & \\
\hline CCL11 & Eotaxin & CCL11 & Ccl11 & CCR3, CCR5 & Eosinophil and basophil migration \\
\hline CCL20 & $\mathrm{MIP}-3 \alpha$ & CCL20 & Ccl20 & CCR6 & Th17 responses, B cell and DC homing \\
\hline CXCL1 & $\begin{array}{l}\mathrm{GRO} \alpha \\
\mathrm{Gm1960} \text { (mouse) }\end{array}$ & CXCL1 & $\mathrm{Cxcl3}$ & CXCR2 & Neutrophil trafficking \\
\hline CXCL3 & $\begin{array}{l}\mathrm{GRO} \gamma \\
\mathrm{KC} \text { (mouse) }\end{array}$ & CXCL3 & $\mathrm{CxCl} 1$ & CXCR2 & \\
\hline CXCL4 & PF4 & PF4 & - & CXCR3-B & Procoagulant \\
\hline CXCL4L1 & PF4V1 & PF4V1 & Pf4 & CXCR3-B & \\
\hline CXCL8 & IL-8 & IL-8 & - & CXCR1, CXCR2 & Neutrophil trafficking \\
\hline CXCL9 & MIG & CXCL9 & Cxc/9 & CXCR3 & $\mathrm{T}$ cell and NK cell trafficking \\
\hline CXCL10 & $\mid \mathrm{P}-10$ & CXCL10 & Cxcl10 & CXCR3 & \\
\hline
\end{tabular}

a Modified from Zlotnik and Yoshie (2012) and Griffith et al. (2014).

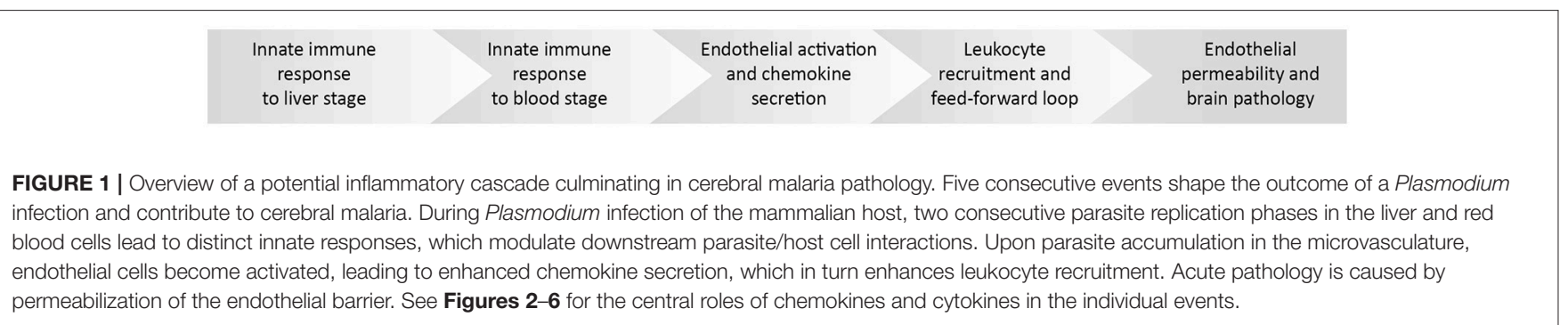

including neurological complications such as sepsis-associated encephalopathy (De Backer et al., 2002; Clark et al., 2004). Strikingly, systemic cytokine levels have been described to correlate with disease severity in malaria as well as sepsis (Prakash et al., 2006; Bozza et al., 2007). These findings corroborate an earlier proposal that an imbalance in pro- and anti-inflammatory immune responses triggers immune-induced pathology and might be a leading cause of CM pathogenesis, which may be further amplified by sequestration (Clark and Rockett, 1994). In addition to inflammation and sequestration, $\mathrm{CM}$ is associated with endothelial activation and increased blood-brain barrier permeability, and these processes might act reciprocally and have synergistic effects (van der Heyde et al., 2006). In line with this notion, certain PfEMP1 variants, which are associated with $\mathrm{CM}$, were described to compete with activated protein C in binding to EPCR (Turner et al., 2013; Bernabeu et al., 2016). Therefore, the anti-coagulant, anti-inflammatory, cytoprotective properties, which are induced upon interaction of protein $\mathrm{C}$ with EPCR, might be impeded by PfEMP1-EPCR interaction and consequently, disease mechanisms may be further exacerbated (Bernabeu and Smith, 2017; Wassmer and Grau, 2017). However, the impact of the interaction between
PfEMP1 and EPCR on inflammation and coagulation remains to be demonstrated.

Insights into the mechanisms underlying CM in humans are limited and mostly based on post mortem histopathology or correlations of serum parameters with disease outcome (Hunt and Grau, 2003). Despite potential differences in human and murine CM pathogenesis (Riley et al., 2010; Craig et al., 2012), $P$. berghei (strain ANKA) infection reliably causes signature symptoms of $\mathrm{CM}$ in susceptible C57BL/6 mice (de Souza and Riley, 2002; Hunt and Grau, 2003). This host-parasite combination is a widely used and well-established murine model for CM, termed experimental cerebral malaria (ECM), which permits mechanistic studies (Craig et al., 2012). Consequently, studies highlighted in this review include reports on human cerebral malaria cases combined with mechanistic insights based on the murine ECM model and in vitro studies.

\section{INNATE IMMUNE ACTIVATION DURING LIVER STAGE DEVELOPMENT}

Upon transmission by the bite of an infective Anopheles mosquito, Plasmodium sporozoites rapidly migrate to the liver, 
invade hepatocytes and develop into thousands of merozoites. Since this developmental stage of Plasmodium parasites is clinically silent, the immune response mounted by the host in order to limit parasite expansion during liver stage development remains largely unexplored (Hafalla et al., 2011). However, it seems likely that sporozoite and liver stage recognition primes the innate immune system locally and well below the pyrogenic threshold. In fact, innate immune cells have occasionally been observed to surround $P$. berghei-infected hepatocytes, indicating that Plasmodium does not remain undetected during liver stage development (Liehl and Mota, 2012). Additionally, a type I interferon (IFN) response is induced in livers of mice infected with P. yoelii or P. berghei (Liehl et al., 2014; Miller et al., 2014). Such an initial type I IFN response might induce chemokines, including IFN- $\gamma$-inducible protein 10 (IP-10)/CXCL10, which in turn could recruit cells expressing the corresponding chemokine receptor CXCR3, such as T, natural killer (NK), and NKT cells, to the site of infection, which might contribute to the local immune response by IFN- $\gamma$ secretion (Figure 2; Liehl et al., 2014; Miller et al., 2014). In good agreement, an increase in IFN- $\gamma$ plasma concentration prior to onset of detectable bloodstage infection was reported in controlled human $P$. falciparum infection (Hermsen et al., 2003). Clearly, the initial cytokine response fails to arrest liver stage development and, thus, does not curtail the proceeding to erythrocyte infection. Interestingly, $P$. berghei sporozoite and blood stage infections result in ECM symptoms in a similar time frame (Kordes et al., 2011), suggesting that immune responses against liver stages might not modulate $\mathrm{CM}$ pathogenesis. Whether this first immune response reduces

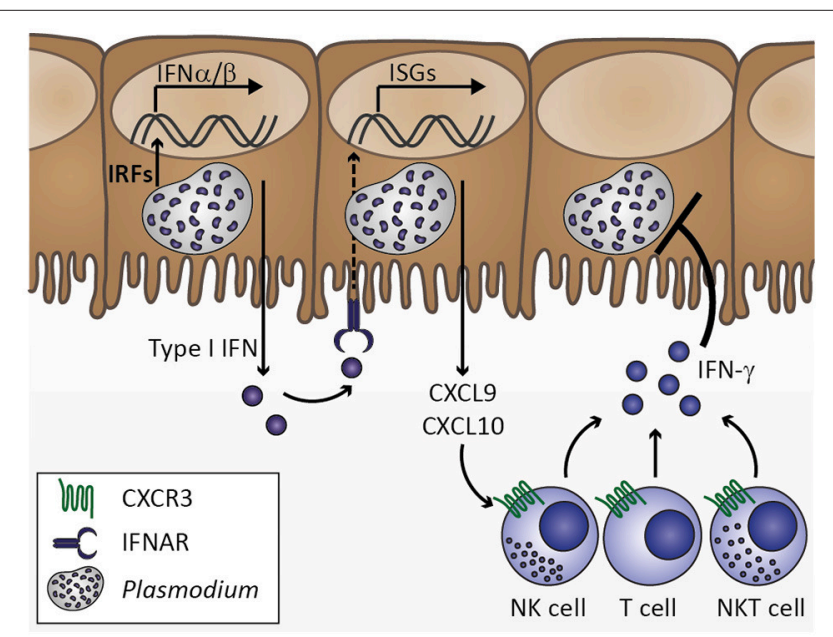

FIGURE 2 | Innate immune response to Plasmodium liver stage infection. Plasmodium infection of hepatocytes activates interferon regulatory factors (IRF), which induce transcription of type I interferons (IFN) IFN $\alpha$ and IFN $\beta$. Secretion of type I IFNs activates IFN $\alpha / \beta$ receptor IFNAR in an autocrine or paracrine manner. IFNAR signaling results in transcription of IFN-stimulated genes (ISGs), which includes chemokines, such as CXCL9 and CXCL10. Upon secretion from hepatocytes, these chemokines might recruit cells expressing the corresponding chemokine receptor CXCR3, including natural killer (NK), T, and NKT cells. Upon activation by type I IFN at the site of infection, these cell types could contribute to limiting Plasmodium liver stage expansion by IFN- $\gamma$ secretion. Based on Liehl et al. (2014) and Miller et al. (2014). the initial parasite number released into the blood stream and thereby influences the magnitude of early blood stage-induced immune responses remains to be tested.

\section{BLOOD STAGE-INDUCED INNATE IMMUNE RESPONSES}

Concomitant with the release of merozoites into the bloodstream and infection of erythrocytes, a Plasmodium infection progresses from the clinically silent liver stage to the symptomatic blood stage. Merozoites are only very briefly ( $\sim 60 \mathrm{~s})$ exposed to the immune system before they rapidly enter new erythrocytes (Gilson and Crabb, 2009; Beeson et al., 2016), and blood stage infection is the exclusive cause of malaria symptoms, which is associated with systemic inflammation and fever. Fever is a common and effective host defense against microbial pathogens and swiftly initiated upon the first host-pathogen interaction. The febrile response is likely triggered through a universal mechanism, in which pyrogens, such as the proinflammatory cytokines interleukin $1 \alpha$ (IL-1 $\alpha)$, IL-1 $\beta$, IL-6, or tumor necrosis factor (TNF), are secreted by innate immune cells upon recognition of pathogen-associated molecular patterns (PAMPs) or host-derived danger-associated molecular patterns (DAMPs) by pattern recognition receptors (PRRs) (Evans et al., 2015). In Plasmodium infection, the characteristic recurrent fever coincides with synchronized rupture of infected erythrocytes in the schizont stage (Oakley et al., 2011). Release of parasite- and host-derived molecules due to erythrocyte rupture was described to induce TNF in vitro (Kwiatkowski et al., 1989; Bate and Kwiatkowski, 1994), and peaks in TNF serum concentration were found to coincide with elevated body temperature during $P$. vivax infection (Karunaweera et al., 1992), indicating that malaria fever is elicited by repeated release of PAMPs and DAMPs. Although an increase in core body temperature is associated with resolution of infection (Oakley et al., 2011), such a proinflammatory immune response needs to be counterbalanced by anti-inflammatory mechanisms in order to avoid a dysregulated immune response, which might lead to complications such as cerebral malaria.

The innate immune system represents the first line of defense against pathogens and mediates recognition and clearance of Plasmodium parasites (Figure 3). Cells of the innate immune system such as macrophages and dendritic cells (DCs) as well as non-professional immune cells such as endothelial cells and fibroblasts express PRR. These include Toll-like receptors (TLR), C-type lectin receptors (CLR), Retinoic acid-inducible gene (RIG)-I-like receptors, and NOD-like receptors (NLR), which recognize PAMPs and host-derived DAMPs (Takeuchi and Akira, 2010). Most malaria PAMPs and DAMPs known so far are apparently recognized by TLR. Activation of TLR initiates a signaling cascade including the adaptor protein MyD88 and the transcription factors NF- $\mathrm{B}, \mathrm{AP}-1$, and interferon regulatory factor (IRF). As a consequence, expression of genes encoding pro-inflammatory cytokines such as type I IFN, IFN- $\gamma$, IL-6, IL12, and TNF, is induced (Eriksson et al., 2013; Gazzinelli et al., 2014). 


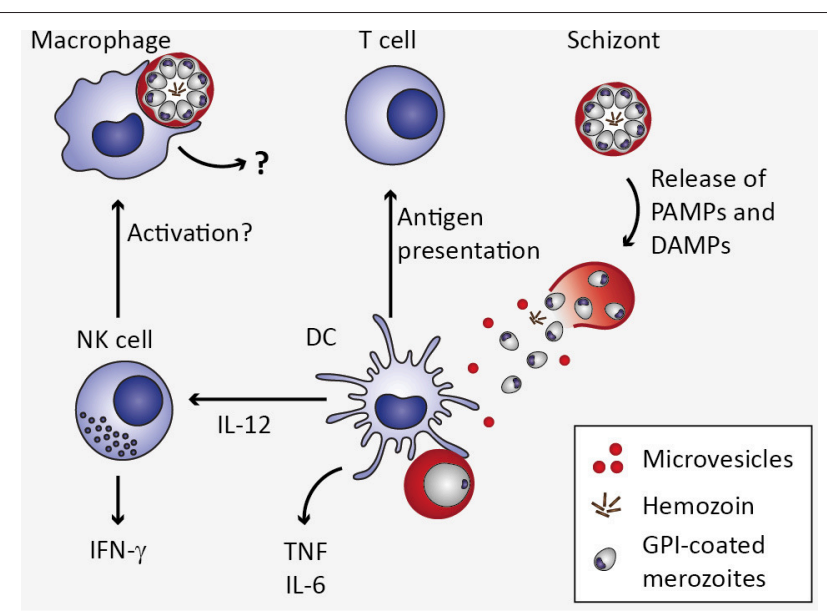

FIGURE 3 | Innate immune response to Plasmodium blood stage infection in the spleen. Macrophages as well as dendritic cells (DC) remove infected erythrocytes from the circulation by phagocytosis. In macrophages, uptake of infected erythrocytes might not lead to secretion of pro-inflammatory cytokines due to phagosomal acidification (Wu et al., 2015). Upon rupture of infected erythrocytes, pathogen-associated molecular patterns (PAMPs) and danger-associated molecular patterns (DAMPs) are released, including microvesicles, hemozoin, and glycosylphosphatidylinositols (GPI). These potential PAMPs and DAMPs might be recognized by DC through pattern recognition receptors, resulting in the secretion of interleukin 12 (IL-12), tumor necrosis factor (TNF), and IL-6 (Wu et al., 2015). DC-derived IL-12 might activate natural killer (NK) cells, which in turn secrete interferon $\gamma(\mathrm{IFN}-\gamma)$ and could thereby activate macrophages (Stevenson and Riley, 2004).

Several Plasmodium-derived molecules have been recognized as malaria PAMPs based on their ability to induce cytokine responses in vitro (Figure 3). One of the candidate malaria PAMPs are glycosylphosphatidylinositols (GPI). Although GPI are present in all eukaryotic cells where they serve as membrane anchors for certain cell surface proteins, Plasmodium GPI are structurally distinct from human GPI (Gowda, 2007). Consequently, Plasmodium GPI moieties may be recognized by the host immune system. Indeed, $P$. falciparum GPI were reported to induce the pro-inflammatory cytokines TNF and IL$1 \beta$ in murine macrophages in vitro (Schofield and Hackett, 1993; Tachado et al., 1996). Moreover, purified GPI immobilized on gold particles elicited pronounced TNF responses from murine macrophages in vitro (Krishnegowda et al., 2005; Zhu et al., 2009, 2011), which was attributed to recognition of $P$. falciparum GPI through TLR2 or heterodimers of TLR2/1 and TLR2/6 (Krishnegowda et al., 2005; Zhu et al., 2011). However, given that TLR-deficiency did not impair immune responses elicited by $P$. berghei ANKA in vivo and did not protect mice from ECM (Togbe et al., 2007; Lepenies et al., 2008), the mechanism of GPI-induced innate immune activation in vivo remains to be determined.

Another potential malaria PAMP is hemozoin, an insoluble polymer formed inside the digestive vacuole to detoxify heme and its conjugated redox-active iron, which is released during hemoglobin proteolysis (Francis et al., 1997; Sigala and Goldberg, 2014). Hemozoin becomes accessible during erythrocyte rupture and upon phagocytosis of infected erythrocytes, and has been described to induce expression of pro-inflammatory cytokines, such as TNF and IL-1 $\beta$, as well as chemokines from human monocytes, murine macrophages (Olivier et al., 2014), and human monocyte-derived DCs (Bujila et al., 2016). Hemozoin or hemozoin-bound nucleic acids are recognized by endosomal TLR9 (Coban et al., 2005; Parroche et al., 2007), cytoplasmic inflammasomes, or cytoplasmic sensors (Kalantari et al., 2014). However, it remains unresolved whether hemozoin itself or molecules bound to hemozoin, such as DNA, activate TLR9 (Liehl and Mota, 2012). In fact, the AT-rich Plasmodium genomic DNA, a feature shared by many pathogens including Schistosoma, was described to be immunomodulatory in vitro, but this response is apparently TLR9-independent (McCutchan et al., 1984; Sharma et al., 2011).

In addition to inducing pro-inflammatory responses, recognition of parasites and Plasmodium-infected erythrocytes is crucial for the phagocytic uptake and thus removal of parasites from the circulation by macrophages and DCs (McGilvray et al., 2000; Stevenson and Riley, 2004; Figure 3). Interestingly, although macrophages and DCs may both contribute to early pro-inflammatory cytokine responses via activation of PRRmediated signaling, a recent study suggests that macrophage responsiveness is strongly compromised upon phagocytosis of $P$. falciparum- or $P$. berghei-infected erythrocytes or free merozoites due to pronounced phagosomal acidification ( $\mathrm{Wu}$ et al., 2015). Instead, DCs contribute to increased serum levels of pro-inflammatory cytokines early during $P$. berghei infection, including IL-6, IL-12p40, and TNF (Wu et al., 2015).

Apart from parasite-derived stimuli, host-derived DAMPs such as urate crystals, heme, and microvesicles released from damaged host cells may activate the innate immune system, although so far this has only been demonstrated for microvesicles (Gazzinelli et al., 2014). Plasmodium falciparuminfected erythrocyte-derived microvesicles have been reported to induce TNF and IL-10 from monocyte-derived human macrophages in vitro, potentially through phagocytic uptake of microvesicles (Mantel et al., 2013). In line with this observation, plasma microparticles derived from $P$. berghei -infected mice stimulated bone marrow-derived macrophages to secrete TNF in vitro, and TNF induction was reported to be TLR4-dependent (Couper et al., 2010). In humans, increased numbers of plasma microparticles have been detected during $P$. falciparum and $P$. vivax infection, and microparticle numbers were higher in severe malaria cases, including $\mathrm{CM}$, than in uncomplicated $P$. falciparum infections (Campos et al., 2010; Nantakomol et al., 2011; Sahu et al., 2013). Furthermore, two studies point toward infection-induced alterations in the microvesicle cargo, suggesting that not only microvesicle frequency but also content are relevant in inducing pro-inflammatory responses (Couper et al., 2010; Tiberti et al., 2016). Together, these studies indicate that microvesicles might contribute to $\mathrm{CM}$ pathogenesis and to other manifestations of severe malaria, and the association with pro-inflammatory immune responses warrants further investigations.

Although parasite-derived stimuli have been repeatedly reported to induce pro-inflammatory responses, the real qualitative and quantitative nature of the stimuli remains 
inadequately understood and may point toward a complex synergistic effect of multiple stimuli. Pro-inflammatory cytokines such as TNF, IL-1 $\alpha$ (Kwiatkowski et al., 1990; Tchinda et al., 2007), IFN- $\gamma$ and IL-12p40 (Hermsen et al., 2003), as well as chemokines, including IL-8/CXCL8 (Hermsen et al., 2003), platelet factor 4 (PF4)/CXCL4, and IP-10/CXCL10 (Wilson et al., 2011), are clearly elevated during $P$. falciparum infection. Several cytokines and chemokines, including TNF and CXCL10, have been found to be associated with CM severity (Kwiatkowski et al., 1990; Wilson et al., 2011), while a more recent study reported that neither plasma nor cerebrospinal fluid (CSF) TNF concentration were indicative of CM-associated mortality, yet elevated levels of TNF in CSF of pediatric CM cases were associated with long-term neurologic and cognitive deficits (Shabani et al., 2017). Consequently, it remains to be conclusively determined which cytokines and/or chemokines present suitable prognostic signatures of disease progression.

While many early studies focused on the identification of single inflammatory cytokines critically involved in malaria pathology, it is likely that numerous immune players are modulated during the course of a Plasmodium infection sequentially and/or simultaneously. Accordingly, it is conceivable that a complex interplay of immune mediators contributes to the development of severe malaria in general, and to CM pathogenesis in particular. Several studies have addressed this issue by systematically analyzing pro- and anti-inflammatory markers. Since these studies included patients from different study sites of varying age and at various time points of infection, the cytokines identified to be associated with disease severity varied substantially, and the combination of selected analytes was heterogenous between studies (Prakash et al., 2006; Jain et al., 2008; Thuma et al., 2011). An early study reported two clusters of cytokines associated with mild and cerebral malaria, respectively, in P. falciparum-infected adults (Prakash et al., 2006). According to this study, IFN- $\gamma$, IL-2, IL-5, IL- 6 and IL-12 were increased in mild malaria whereas TGF- $\beta$, TNF, IL-10 and IL- $1 \beta$ were particularly elevated in CM. In a study cohort of $P$. falciparuminfected children and adults, serum TNF levels did not correlate with disease severity, and instead IP-10/CXCL10, sTNF-R2, and sFas were proposed as biomarkers of CM severity and mortality (Jain et al., 2008). Additional cytokines were elevated in malaria cases compared to healthy controls and included IL-1ra, IL-10, IL-8/CXCL8, and macrophage inflammatory protein $1 \beta$ (MIP-

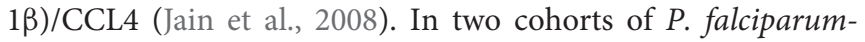
infected children, TNF concentration was slightly, albeit nonsignificantly, elevated in CM compared to severe anemia cases (Thuma et al., 2011; Mandala et al., 2017). In the study by Thuma et al. (2011) conducted in Zambia, IL-10, IL-1 $\alpha$, IL-6, and IP10/CXCL10 plasma levels were higher in children suffering from CM than in children with severe anemia (Thuma et al., 2011). In line with these findings, Mandala et al. (2017) found higher IL-10 and IL-6 serum levels in Malawian children suffering from CM compared to those with severe anemia, while IFN- $\gamma$ and IL-8/CXCL-8 were also elevated in pediatric CM cases.

In summary, cytokine profiling continues to aid in identifying distinct patterns of pro- and anti-inflammatory cytokines and chemokines in $\mathrm{CM}$ patients. Although a common cytokine/chemokine signature associated with CM severity has not yet been identified, which is in part due to the fact that the combination of markers investigated varies among studies, collectively, these studies point toward important roles for certain immunoregulatory molecules in modulating CM severity. In order to describe how inflammatory mediators associated with Plasmodium infection may contribute to CM pathogenesis, we will highlight their roles in endothelial activation, blood-brain barrier permeability, and neuroinflammation, by drawing on findings obtained from in vitro studies and the murine ECM model.

\section{INFLAMMATION AND ENDOTHELIAL ACTIVATION}

Functions of healthy endothelium include anti-coagulant properties through inhibiting platelet adhesion and aggregation, regulation of blood flow by releasing nitric oxide, controlling endothelial permeability, preventing extravasation of plasma proteins to tissue, and preventing leukocyte adhesion through suppressing adhesion molecule expression and sequestering chemokines within Weibel-Palade-bodies (Pober and Sessa, 2007). Under inflammatory conditions such as systemic inflammation during Plasmodium infection, endothelial activation may seriously impair endothelial function (Figure 4). A hallmark of endothelial activation is the expression of adhesion molecules such as VCAM-1 and ICAM-1 on the endothelial cell surface. Systemic endothelial activation was reported in $P$. falciparum-infected and in sepsis patients based on plasma levels of soluble adhesion molecules (Turner et al., 1998). Moreover, immunohistochemical analysis of fatal P. falciparum -infected CM cases revealed that expression of ICAM-1 was

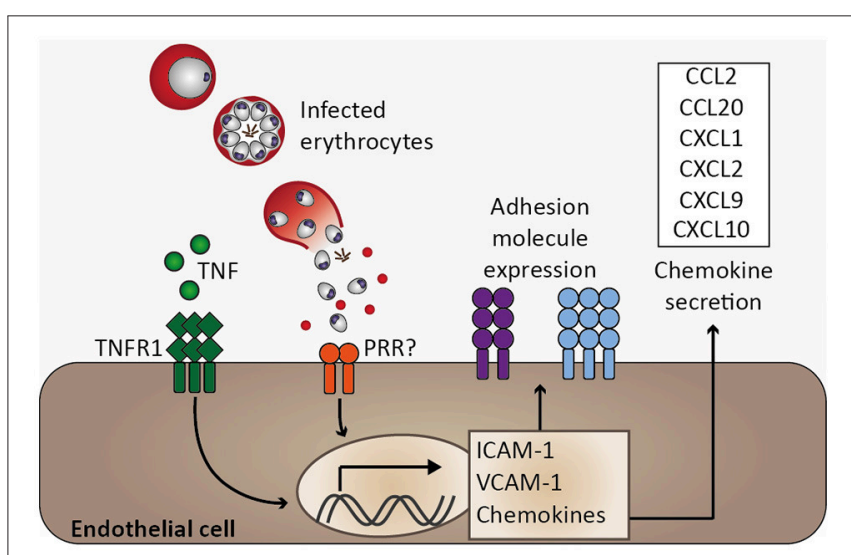

FIGURE 4 | Endothelial activation and chemokine secretion. A characteristic feature of Plasmodium infection is endothelial activation, which is likely induced by elevated serum tumor necrosis factor (TNF) levels. Binding of TNF to its receptor (TNFR1) induces transcription of adhesion molecules, including ICAM-1 and VCAM-1, as well as chemokines (Pober and Sessa, 2007). Endothelial activation might be directly induced by infected erythrocytes, possibly through activation of pattern recognition receptors (PRR), resulting in elevated expression of ICAM-1 and chemokine secretion (Viebig et al., 2005; Tripathi et al., 2006, 2009; Chakravorty et al., 2007). 
most pronounced in the brain microvasculature compared to other organs and biopsies from non-malaria cases (Turner et al., 1994). In good agreement, ICAM-1 staining was described to be more pronounced on brain endothelial cells from $P$. berghei (strain ANKA)-infected mice during ECM than in those isolated from P. yoelii-infected (non-ECM) mice (Grau et al., 1991). Accordingly, Icam1-deficiency protected mice from P. berghei-induced ECM (Favre et al., 1999). Considering that adhesion molecules are thought to promote binding of infected erythrocytes and leukocytes to endothelial cells, and that human as well as murine CM is associated with intravascular accumulation of leukocytes in the brain (Hunt and Grau, 2003), these findings signify a critical role for endothelial activation in CM pathogenesis.

Among other factors, endothelial activation may be induced by inflammatory cytokines. TNF and lymphotoxin $\alpha$ (LT $\alpha)$ activate human endothelial cells in vitro (Cavender et al., 1989; Pober and Cotran, 1990). Similarly, IFN- $\gamma$, IL- $1 \alpha$, and IL- $1 \beta$ function in endothelial activation (Pober and Cotran, 1990; Bauer et al., 2002). These pro-inflammatory cytokines have been found to be elevated in serum or plasma of $P$. falciparum-infected patients and TNF as well as IL- $1 \alpha$ and IL-1 $\beta$ were described to be associated with CM severity (Prakash et al., 2006; Thuma et al., 2011). Consequently, endothelial activation observed in $P$. falciparum infection might in part be mediated by these cytokines. In accordance with a proposed role for endothelial activation in CM, the pathology observed in murine ECM is associated with a $\mathrm{T}$ helper 1 (Th 1) immune response, and cytokines, such as IFN- $\gamma$, TNF, and LT $\alpha$, and immune cells, e.g., $\mathrm{CD}^{+}$and $\mathrm{CD}^{+} \mathrm{T}$ cells together with $\mathrm{NK}$ cells are involved in ECM (Yanez et al., 1996; Lucas et al., 1997; Engwerda et al., 2002; Hunt and Grau, 2003; Schofield and Grau, 2005; Langhorne et al., 2008). Of note, despite an association of TNF with disease severity in CM, Tnf-deficient mice were not protected from ECM (Engwerda et al., 2002), and blocking of TNF by antiTNF antibodies or pentoxifylline did not improve survival in human CM (Di Perri et al., 1995; van Hensbroek et al., 1996). Consequently, blocking TNF was demonstrated to be insufficient to prevent fatal $\mathrm{CM}$, and, therefore, additional mechanisms are likely to critically contribute to CM pathogenesis. Moreover, these early therapeutic interventions highlight the complexity of this malaria syndrome, indicating that single serum cytokines associated with $\mathrm{CM}$ severity do not necessarily translate into therapeutic approaches. Notably, elevated serum TNF in particular may represent a secondary immune response, which might further amplify severity while not being critical in initiating CM pathogenesis.

Apart from the induction of endothelial activation by proinflammatory cytokines, endothelial cells are an important part of the innate immune response since they recognize PAMPs through expression of PRR such as TLR and NLR. Endothelial cells were found to secrete pro-inflammatory cytokines, including IL- $1 \alpha$, IL- $1 \beta$, or IL-6, as well as immunomodulatory cytokines, namely IL-10 and TGF- $\beta$, and chemokines, e.g., monocyte chemoattractant protein 1 (MCP-1)/CCL2, RANTES/CCL5, and IL-8/CXCL8, upon stimulation by proinflammatory cytokines or lipopolysaccharide (LPS) in vitro
(Mai et al., 2013). Notably, microvascular endothelial cells derived from subcutaneous adipose tissue of patients with uncomplicated malaria and fatal CM were demonstrated to differ in their endothelial inflammatory response to TNF stimulation ex vivo in that MCP-1/CCL2 and IL- 6 were induced to a larger extent in endothelial cells derived from CM patients. Consequently, it was proposed that inter-individual differences in the endothelial response to inflammation might account for CM severity (Wassmer et al., 2011). These results support the notion that the pro-inflammatory microvascular environment during P. falciparum infection might be enhanced by endothelial cells. Interestingly, human brain microvascular endothelial cells have been described to phagocytose $P$. berghei merozoites in vitro (Howland et al., 2015b). Furthermore, upon co-culture with $P$. falciparum-infected erythrocytes, human endothelial cell lines were reported to upregulate ICAM-1 expression (Viebig et al., 2005; Tripathi et al., 2006), to increase transcription of CCL20, CXCL1, CXCL2, CXCL8, and IL6 (Tripathi et al., 2009), and to secrete MCP-1/CCL2, MIP-3 $\alpha / C C L 20$, and IL-8/CXCL8 (Viebig et al., 2005; Chakravorty et al., 2007) (Figure 4). Together, these in vitro observations suggest that endothelial cells are potentially directly involved in the immune response to Plasmodium infection. Since leukocyte sequestration in the microvasculature of the brain was described in human CM and murine ECM (Hunt and Grau, 2003), local chemokine gradients originating from brain endothelial cells might orchestrate leukocyte migration and thus promote local inflammation, thereby contributing to the development of CM.

Although the extent of the contribution of endothelial cellderived chemokines in the process of leukocyte accumulation in brains of patients suffering from CM and of ECM mice remains to be established, a number of clinical studies reported that several chemokines are elevated in serum and CSF of CM patients, thereby providing a potential link between serum or CSF chemokine levels and progression from mild malaria to CM. Chemokines that were elevated in human CM cases included MCP-1/CCL2, MIP-1ß/CCL4, PF4/CXCL4, IL-8/CXCL8, and IP-10/CXCL10 (Jain et al., 2008; Wilson et al., 2011). Particularly, MCP-1/CCL2, Eotaxin/CCL11, and IP10/CXLC10 were reported to be indicative of disease severity (Armah et al., 2007; Jain et al., 2008; Thuma et al., 2011;

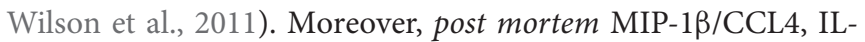
8/CXCL8, and IP-10/CXCL10 levels were significantly elevated in cerebrospinal fluid (CSF) of fatal P. falciparum-induced CM cases when compared to fatal severe malarial anemia cases and non-malaria deaths (Armah et al., 2007). In another study, IL-8/CXCL8 was elevated in CSF of non-fatal CM cases of P. falciparum-infected children (John et al., 2008b), while MCP-

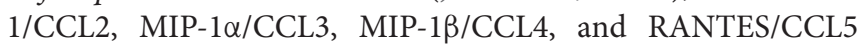
levels were comparable to malaria-free controls. The relevance of certain chemokines in cerebral malaria pathogenesis was demonstrated in the murine ECM model, in which Cxcl4-, Cxcl9-, or Cxcl10-deficiency resulted in reduced ECM-associated mortality (Campanella et al., 2008; Srivastava et al., 2008; Nie et al., 2009). Notably, PF4/CXCL4 was elevated in plasma of $P$. berghei ANKA-infected mice and demonstrated to induce TNF secretion from peritoneal macrophages and T cells in vitro, 
and Cxcl4-deficiency resulted in reduced serum TNF and IFN$\gamma$ levels during $P$. berghei ANKA-infection (Srivastava et al., 2008), indicating that PF4/CXCL4 contributes to establishing a pro-inflammatory environment, which might amplify further immune responses and could thereby promote CM pathogenesis. Furthermore, protection from ECM in Cxcl10-deficient mice was associated with a decrease in leukocyte sequestration in brains of $P$. berghei ANKA-infected mice, while parasite-specific CXCR3 ${ }^{+}$ $\mathrm{T}$ cells were increased in spleens of Cxcl10-deficient compared to WT mice (Nie et al., 2009), suggesting that IP-10/CXCL10mediated recruitment of $\mathrm{CXCR}^{+}{ }^{+} \mathrm{T}$ cells to the brain might contribute to the development of ECM. A similar phenomenon might account for a decrease in ECM-associated mortality described for Cxcl9-deficient mice (Campanella et al., 2008), since recruitment of CXCR3-expressing cells can also be initiated by monokine induced by IFN- $\gamma$ (MIG)/CXCL9. However, the precise mechanism by which MIG/CXCL9 contributes to ECM pathogenesis is yet to be determined. Apart from studies using specific gene deletions, chemokine transcripts were found to be induced to a higher extent in brains of ECM- compared to non-ECM mice. These transcripts included $\mathrm{Ccl} 2, \mathrm{Ccl} 3, \mathrm{Ccl} 4$, Ccl5, Cxcl1, Cxcl9, and Cxcl10 (Miu et al., 2008; Van den Steen et al., 2008), supporting the finding that apart from NK and $\mathrm{T}$ cells, monocytes and neutrophils also sequester in the microvasculature (Renia et al., 2012), e.g., through recruitment by MCP-1/CCL2 and keratinocyte chemoattractant (KC)/Cxcl1, respectively. Nevertheless, studies to identify the cell types producing these chemokines in the brain are very limited. For instance, CXCL9 was demonstrated to be expressed by endothelial cells, while the source(s) of CXCL10 in the brain during $P$. berghei infection remain to be conclusively determined, and could include neurons, astrocytes, or endothelial cells (Campanella et al., 2008; Miu et al., 2008) as well as recruited monocytes (Ioannidis et al., 2016).

Together, activated endothelial cells likely contribute to local inflammation by secreting cytokines and chemokines, thereby recruiting leukocytes, including monocytes, macrophages, neutrophils and T cells, which accumulate in brains of mice and humans during ECM and CM, respectively (Renia et al., 2012; Storm and Craig, 2014). Since these cell types might secrete cytokines and chemokines themselves, local inflammation and endothelial activation could be further exacerbated (Figure 5). For instance, potential endothelial cell-induced recruitment of neutrophils and monocytes expressing IP-10/CXCL10 may promote further recruitment of $\mathrm{CXCR}^{+}$cells such as $\mathrm{NK}$ and $\mathrm{T}$ cells to the brain (Ioannidis et al., 2016).

\section{ENDOTHELIAL ACTIVATION AND BLOOD-BRAIN BARRIER INTEGRITY}

The blood-brain barrier is comprised of endothelial cells forming a continuous barrier through tight junctions, a basement membrane and astrocytes, which are in direct contact with neurons and microglia. This composition is critical to minimize local inflammation and neuronal damage (Obermeier et al., 2013). In the course of Plasmodium infection, endothelial

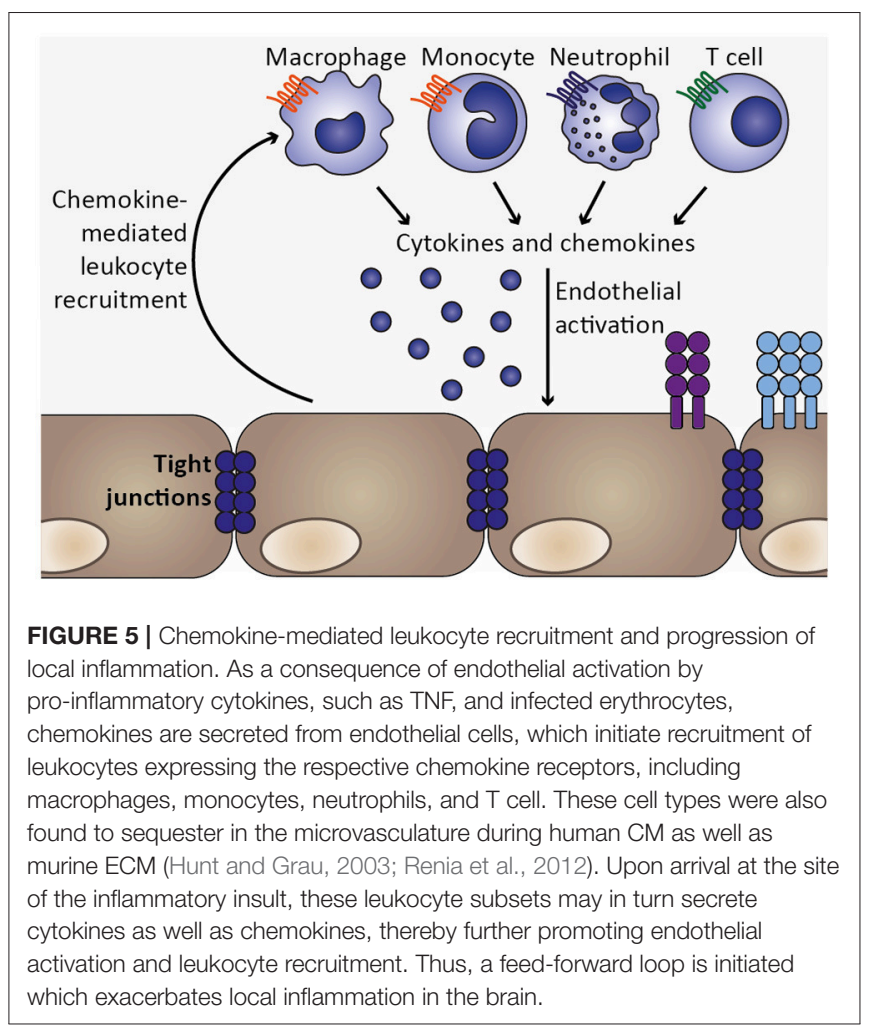

activation may progress to vascular permeability and loss of blood-brain barrier integrity, as indicated by hemorrhages in brains of CM patients and extravasation of dyes or antibodies into the brain parenchyma in ECM (Renia et al., 2012). Although the extent of pathological events related to blood-brain barrier function in human CM is variable, dysfunction of the bloodbrain barrier appears to be associated with progression of cerebral disease (Medana and Turner, 2006). Histology of brain sections from fatal human $\mathrm{CM}$ cases revealed a redistribution of the tight junction proteins occludin, vinculin, and zonula occludens 1 (ZO-1), which are central to blood-brain barrier integrity (Brown et al., 1999). Moreover, immunohistochemistry of brain sections derived from pediatric fatal CM cases indicated blood-brain barrier impairment in areas containing sequestered $P$. falciparum-infected erythrocytes, where they were associated with focal loss of endothelial intercellular junctions (Brown et al., 2001). Additionally, in vitro studies have demonstrated a decrease in endothelial resistance upon addition of $P$. falciparuminfected erythrocytes to endothelial cells (Tripathi et al., 2007; Jambou et al., 2010). This model, however, only partially reflects the response at the blood-brain barrier due to lack of barrier components such as astrocytes and pericytes (Medana and Turner, 2007).

Interestingly, MCP-1/CCL2 induces redistribution of tight junction proteins and increases endothelial permeability in vitro (Stamatovic et al., 2003; Song and Pachter, 2004; Yao and Tsirka, 2011). Thus, chemokines may contribute to organ-specific inflammation by inducing signals that promote endothelial permeability (Figure 6). The roles of the respective chemokine receptors are less clear in this context. This is exemplified in the 


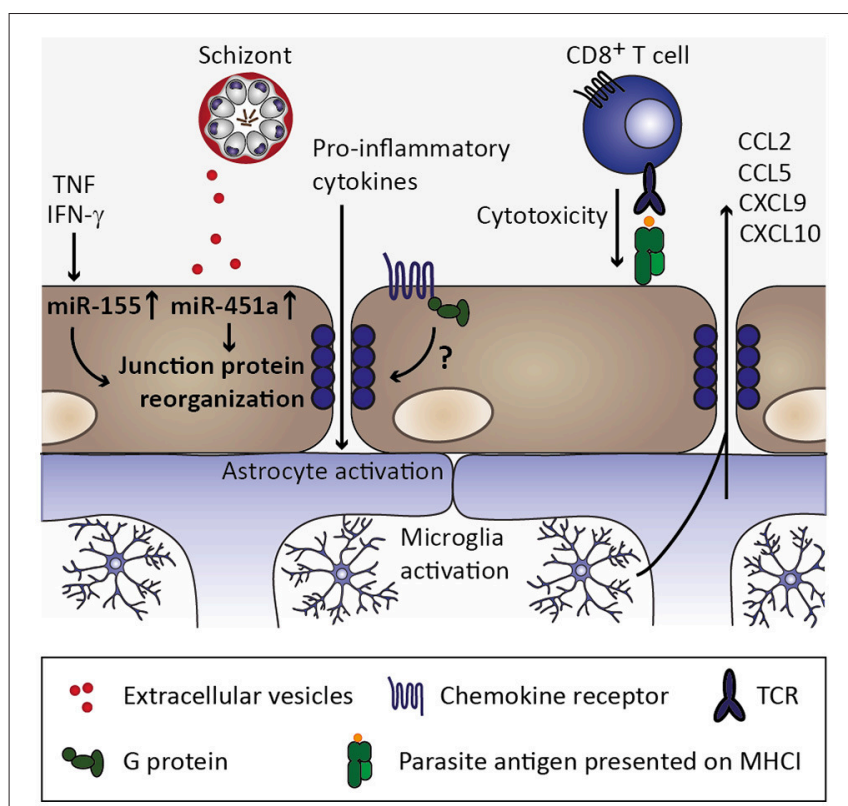

FIGURE 6 | Endothelial permeability and neuroinflammation. Through continued inflammatory insults toward endothelial cells by, for instance, circulating tumor necrosis factor (TNF) and interferon $\gamma$ (IFN- $\gamma$ ), miR-155 might be upregulated in endothelial cells. Along with uptake of miR-451a from P. falciparum-infected erythrocyte-derived extracellular vesicles, reorganization of tight junction proteins such as zonula occludens 1 (ZO-1) is induced and could contribute to endothelial permeability during cerebral malaria (Lopez-Ramirez et al., 2014; Mantel et al., 2016). Additionally, chemokine receptors might induce redistribution of tight junction proteins in a $\mathrm{G}$ protein-dependent manner (Stamatovic et al., 2003; Song and Pachter, 2004; Yao and Tsirka, 2011), while the contribution of chemokine-induced opening of tight junctions is less clear in the context of cerebral malaria. CD8 ${ }^{+} \mathrm{T}$ cell-mediated cytotoxity toward endothelial cells through recognition of parasite antigen presented on MHC class I molecules on endothelial cells likely contributes substantially to blood-brain barrier permeability during cerebral malaria (Howland et al., 2015a,b). Consequently, pro-inflammatory cytokines enter the brain parenchyma and could thereby activate astrocytes and microglia, which in turn could secrete chemokines (Capuccini et al., 2016) and thus promote leukocyte recruitment and local inflammation.

MCP-1/CCL2 receptor CCR2. Ccr2-deficiency abrogated CCL2induced endothelial permeability in vitro (Stamatovic et al., 2003), but did not protect against ECM (Belnoue et al., 2003), indicating that other chemokines and/or additional mechanisms induce blood-brain barrier permeability.

Along with the observed redistribution of endothelial tight junction proteins and loss of intercellular junctions, growing evidence from the murine ECM model suggests that $\mathrm{CD} 8^{+}$ $\mathrm{T}$ cells are primary mediators in CM disease pathogenesis by contributing considerably to the loss of blood-brain barrier integrity (Howland et al., 2015a). Indeed, the accumulation of $\mathrm{CD}^{+}$T cells in brains of $P$. berghei ANKA-infected mice appears to be critical for the development of ECM (Villegas-Mendez et al., 2012), and blood-brain barrier disruption was proposed to be a consequence of $\mathrm{CD}^{+} \mathrm{T}$ cell-mediated cytotoxicity toward endothelial cells cross-presenting parasite antigen (Howland et al., 2015b) (Figure 6). Recruitment of $\mathrm{CD}^{+} \mathrm{T}$ cells to the brain of infected mice has been described to be partly mediated by expression of the chemokine receptor CXCR3 and its IFN- $\gamma$ inducible ligands MIG/CXCL9 as well as IP-10/CXCL10 (Hansen et al., 2007; Villegas-Mendez et al., 2012). Indeed, NK cell-derived IFN- $\gamma$ has been demonstrated to be crucial for the induction of CXCR3 expression on $\mathrm{T}$ cells and subsequent T-cell migration to the brain of $P$. berghei ANKA-infected mice (Hansen et al., 2007). In line with these findings, brain transcripts of Cxcr3 were reduced in mice deficient for IFN- $\gamma \mathrm{R} 1$ in comparison to wild type mice infected with $P$. berghei ANKA. Additionally, while expression of MIG/CXCL9 and IP-10/CXCL10 is induced in brains of $P$. berghei ANKA-infected wild type mice, expression levels of these chemokines in Ifngr1-deficient mice were similar to those of uninfected mice (Palomo et al., 2013). Collectively, these findings suggest that IFN- $\gamma$-induced signaling is crucial for chemokine-mediated leukocyte recruitment to the brain during ECM, while it remains to be established to which extent activated endothelium might contribute to this chemokine response.

Importantly, Cxcr3-deficient mice were less likely to succumb to ECM (Campanella et al., 2008; Miu et al., 2008), and numbers of $\mathrm{CD}^{+}$and $\mathrm{CD}^{+} \mathrm{T}$ cells in brains of Cxcr3-deficient mice were reported to be reduced compared to wild type mice during $P$. berghei ANKA infection. However, the extent of $\mathrm{CD}^{+} \mathrm{T}$ cell recruitment was similar in Cxcr3-deficient mice which were either resistant or susceptible to ECM (Miu et al., 2008). These results indicate that the quantity of $\mathrm{CD}^{+} \mathrm{T}$ cells in brains of $P$. berghei ANKA-infected mice is not critical for the development of ECM. Rather, additional aspects such as $\mathrm{CD}^{+}{ }^{+}$T-cell specificity toward parasite antigen presented on endothelium, expression levels of key cytotoxic effector molecules perforin and granzyme $\mathrm{B}$ by $\mathrm{CD}^{+} \mathrm{T}$ cells, and localization of these $\mathrm{CD} 8^{+} \mathrm{T}$ cells within the brain might play a substantial role in the development of ECM (Miu et al., 2008; Haque et al., 2011; Howland et al., 2015b; Huggins et al., 2017). Nevertheless, it remains to be determined why susceptibility to ECM among Cxcr3-deficient mice is variable. Moreover, these findings indicate that additional mechanisms other than $\mathrm{CD}^{+}$ $\mathrm{T}$ cell-mediated cytotoxicity might be involved in the loss of blood-brain barrier integrity.

In fact, in addition to $\mathrm{CD}^{+} \mathrm{T}$ cells and chemokines, extracellular vesicles derived from $P$. falciparum-infected erythrocytes were recently implicated in blood-brain barrier permeability in vitro (Mantel et al., 2016; Figure 6). These extracellular vesicles contained miRNA miR-451a, which, upon endocytosis by endothelial cells, correlated with reduced endothelial caveolin-1 expression. Interestingly, MCP1/CCL2-induced redistribution of tight junction proteins and concomitant endothelial permeability (Stamatovic et al., 2003) was also accompanied by a decrease in caveolin-1 protein (Song and Pachter, 2004), thus pointing toward a common underlying mechanism in the induction of endothelial permeability by CCL2 and extracellular vesicles derived from $P$. falciparum-infected erythrocytes. Since sequestration of infected erythrocytes in the microvasculature is likely promoted by expression of adhesion molecules upon endothelial activation, locally increased release of $P$. falciparum-infected erythrocyte-derived extracellular vesicles carrying miRNA miR-451a might be an additional 
mechanism involved in blood-brain barrier permeability in CM.

In addition to miR-451a, another miRNA, miR-155, was implicated in inflammation-associated blood-brain barrier permeability. Upon stimulation of human brain endothelial cells with pro-inflammatory cytokines TNF and IFN- $\gamma$ in vitro, miR-155 was found to be upregulated. The tight junction protein claudin-1 was reported to be among the candidate targets of miR-155, and cytokine stimulation or miR-155 overexpression resulted in reorganization of the tight junction protein $\mathrm{ZO}-1$ along with increased endothelial permeability (Lopez-Ramirez et al., 2014), indicating that cytokines such as TNF and IFN- $\gamma$ might directly contribute to blood-brain barrier permeability through induction of regulatory miRNAs. Interestingly, levels of miR-155 were recently reported to be elevated in extracellular vesicles in the circulation of $P$. berghei ANKA-infected mice, and miR-155-deficiency resulted in preservation of blood-brain barrier integrity and reduced ECM-associated mortality (Barker et al., 2017). Notably, plasma concentrations of IL-6, IFN- $\gamma$, and MCP-1/CCL2 were significantly elevated in $P$. berghei ANKA-infected miR-155-deficient compared to wild type mice in this study, suggesting that miR-155 might have additional targets other than tight junction proteins. Importantly, whether miR-155-carrying extracellular vesicles are derived from activated endothelium, and their impact on tight junction reorganization in the context of ECM, remain to be determined. Nevertheless, inhibition of the function of miR-155 might present a useful target for therapeutic approaches (Barker et al., 2017). These processes of chemokine induction, microvascular sequestration of infected erythrocytes and leukocytes, and release of extracellular vesicles carrying regulatory miRNAs are most likely not exclusive to the brain. However, endothelial permeability is likely more detrimental in the brain than in other organs and, hence, cerebral malaria may be the most severe manifestation of these processes. Additionally, brain endothelial cells have been described to express comparably low levels of thrombin-binding thrombomodulin, and excess of unbound thrombin may further promote local endothelial activation by inducing further expression of adhesion molecules (Clark et al., 2006).

Together, cytokine- or Plasmodium-induced endothelial activation may lead to chemokine induction and leukocyte recruitment as well as sequestration of infected erythrocytes, which may act synergistically in promoting endothelial permeability. Nevertheless, the precise molecular mechanisms that trigger loss of blood-brain barrier integrity in $\mathrm{CM}$ are incompletely understood and need to be further investigated.

\section{NEUROINFLAMMATION}

Upon disruption of the blood-brain barrier, cytokines, chemokines, and soluble parasite products might enter the brain parenchyma and, thereby, activate astrocytes and microglia, and result in symptoms of neuroinflammation in the absence of extravasation of infected erythrocytes or leukocytes into the brain parenchyma (Combes et al., 2010). Indeed, activation of microglia and astrocytes has been observed in murine and human CM (Hunt et al., 2006; Combes et al., 2010). For instance, transcriptome analysis of microglia isolated from $P$. berghei-infected mice revealed that several chemokines as well as transcripts related to type I IFN signaling were differentially upregulated (Capuccini et al., 2016). This finding was confirmed in vitro by stimulation of a murine microglia cell line with IFN- $\beta$, which resulted in secretion of MCP-1/CCL2, RANTES/CCL5, MIG/CXCL9, and IP-10/CXCL10. Moreover, stimulation of human primary astrocytes with a combination of IFN- $\gamma$ and LT $\alpha$ synergistically induced IP-10/CXCL10 secretion in vitro (Bakmiwewa et al., 2016). Additionally, co-culture of $P$. berghei-infected erythrocytes with a mixed astrocyte-microglia culture resulted in phagocytic uptake of infected erythrocytes and of parasitized erythrocyte-derived microvesicles by microglia and astrocytes, respectively, which in turn was associated with an induction in IP-10/CXCL10 secretion (Shrivastava et al., 2017). Furthermore, astrocytes and microglia may secrete various cytokines and chemokines upon activation (Dong and Benveniste, 2001; Medana et al., 2001). Consequently, loss of blood-brain barrier integrity and subsequent activation of microglia and astrocytes might result in further chemokine-mediated recruitment of leukocytes to the brain and subsequent amplification of inflammation (Figure 6). Additionally, activation of microglia might induce expression of FasL, which, upon binding to Fas expressed on astrocytes, could induce astrocyte damage (Hunt et al., 2006). However, to our knowledge, this has so far not been demonstrated in the context of CM. Since astrocytes are critically involved in maintaining blood-brain barrier properties and survival of neurons (Combes et al., 2010), their functional impairment might disrupt neuronal activity and could thereby account for the neurological impairment observed in some CM cases (Hunt et al., 2006).

\section{SUMMARY AND PERSPECTIVES}

The human and murine immune system are in part strikingly different (Stevenson and Riley, 2004). For instance, IL-8/CXCL8 was reported to be associated with cerebral malaria (Armah et al., 2007; John et al., 2008b), while this chemokine is not expressed in mice (Viola and Luster, 2008). However, KC/Cxcl1 is considered a functional homolog of IL-8/CXCL8 in mice (Hol et al., 2010), which mediates neutrophil recruitment, and Cxcl1 transcripts were reported to be elevated in brains of ECM compared to non-ECM mice (Miu et al., 2008), suggesting that $\mathrm{KC} / \mathrm{Cxcl} 1$ might be similarly involved in ECM pathogenesis. Yet, the precise contribution of IL-8/CXCL8 and $\mathrm{KC} / \mathrm{Cxcl1}$ to human CM and murine ECM, respectively, needs to be further investigated. Moreover, the murine ECM model shares several features with human CM, including aspects of histopathology and inflammatory responses. Importantly, mechanistic insights can only be gained from the murine ECM model, and many observations are in remarkably good agreement with clinical data obtained from P. falciparuminduced CM. Although a comprehensive representation of the 
events leading to $\mathrm{CM}$ pathogenesis remains elusive, a working model of an inflammatory cascade leading to CM is conceivable (Figure 1).

Upon establishing liver stage infection, a first type I IFN response is mounted by hepatocytes, leading to a primary activation of IFN- $\gamma$-producing NK cells (Liehl et al., 2014; Miller et al., 2014; Figure 2) and, consequently, induction of MIG/CXCL9 and IP-10/CXCL10 secretion, potentially from endothelial cells (Campanella et al., 2008; Miu et al., 2008). Upon progression of the Plasmodium infection to the blood stages, infected erythrocytes are recognized by DCs and induce the secretion of IL-12 and TNF (Wu et al., 2015; Figure 3). IL-12 contributes to further activation of NK and differentiation of Th1 cells (Stevenson and Riley, 2004), while TNF and IFN- $\gamma$ activate chemokine transcription and adhesion molecule expression on endothelial cells (Pober and Sessa, 2007; Miu et al., 2008; Griffith et al., 2014). As the infection progresses further, Plasmodiuminfected erythrocytes are recognized by endothelial cells and induce expression of chemokines, such as MCP-1/CCL2 and IL8/CXCL8 (Viebig et al., 2005; Chakravorty et al., 2007; Tripathi et al., 2009; Figure 4). As a result, leukocytes are recruited, including monocytes, macrophages, neutrophils, as well as $\mathrm{T}$ cells, and initiate a local inflammatory response (Renia et al., 2012; Storm and Craig, 2014; Figure 5). These cell types secrete chemokines, thereby amplifying the response leading to further leukocyte recruitment and intensifying local inflammation. Additionally, endothelial cells phagocytose merozoites and parasite material released during schizont rupture and present parasite antigens to $\mathrm{CD}^{+} \mathrm{T}$ cells (Howland et al., 2015b; Figure 6), which may result in targeted elimination of antigenpresenting endothelial cells and, thus, cause damages to the endothelial lining of the blood-brain barrier. This process can be further exacerbated by openings of tight junctions mediated by chemokines and extracellular vesicle-derived miRNAs (Song and Pachter, 2004; Mantel et al., 2016). As a result, small molecules can enter the brain parenchyma and potentially activate brain-resident microglia and astrocytes, further amplifying local inflammation through cytokine secretion and leukocyte recruitment and impairing neuronal functionality (Hunt et al., 2006; Combes et al., 2010).

Even though the febrile response elicited during Plasmodium blood stage infection together with the concomitant inflammatory cytokine responses limit parasite growth and mediate the resolution of infection, imbalances in pro-inflammatory and anti-inflammatory cytokines cause progression of malaria disease to manifestations of severe malaria, such as CM, and death. Adjunctive therapies that prevent adverse effects of the immune response to Plasmodium infection are therefore urgently needed. Although immunomodulation is a promising approach to alleviate immune-mediated pathology, such therapies need to be designed carefully in order to maintain efficient control of parasite growth. Notably, adjunct therapies modulating chemokine responses may have fewer side-effects compared to therapies based on neutralizing cytokines (Ioannidis et al., 2014). Indeed, antibodymediated targeting of IP-10/CXCL10 was demonstrated to result in reduced ECM-induced mortality and parasite burden in mice, which was likely mediated by retention and expansion of parasite-specific T cells in the spleen (Nie et al., 2009). Such treatments may be relevant in other contexts as well: murine Toxoplasma encephalitis has been described to be associated with constant expression of $\mathrm{Ccl} 2, \mathrm{Ccl} 3, \mathrm{Ccl} 4, \mathrm{Ccl} 5$, and Cxcl10 in brains of infected mice concomitant with continuous recruitment of $\mathrm{CD}^{+}$and $\mathrm{CD} 8^{+} \mathrm{T}$ cells, which was not the case for mice in which the infection developed into chronic latency (Strack et al., 2002). Furthermore, targeted neutralization of single chemokines, including MCP-1/CCL2, MIP-1 $\alpha /$ CCL3, RANTES/CCL5, or IP-10/CXCL10, resulted in protection of mice from experimental autoimmune encephalomyelitis, a murine model for multiple sclerosis (Karin and Wildbaum, 2015). These findings from other neuroinflammatory diseases highlight that chemokines might present a valuable target for intervention strategies in several diseases. However, efforts to design chemokine-based therapies are challenged by the complexity of the chemokine system as well as properties such as redundancy, pleiotropy, and speciation (Viola and Luster, 2008). In fact, most cell populations express several different chemokine receptors and thus single chemokine or chemokine receptor blockade may not affect disease outcome in certain pathological conditions.

Together, reliable biomarkers which predict disease outcome and allow for potential prophylactic measures are yet to be identified. Several clinical studies have reported potential diagnostic and prognostic biomarkers for CM, which apart from chemokines such as IP-10/CXCL10 and PF4/CXCL4 also include $P$. falciparum histidine-rich protein 2 (PfHRP2), a protein which correlates with parasite biomass, as well as regulators of endothelial activation angiopoietin-1 and -2 (summarized in Sahu et al., 2015). Still, comprehensive studies with defined clinical parameters and systematic assessment of plasma levels of multiple inflammatory mediators need to be performed to determine whether distinct clusters of markers can be associated with disease severity in order to identify patients at risk of developing CM early during infection. Such studies will inform future investigations into mechanisms underlying disease pathogenesis in order to develop novel evidence-based malaria intervention strategies.

\section{AUTHOR CONTRIBUTIONS}

All authors listed have made a substantial, direct and intellectual contribution to the work, and approved it for publication.

\section{ACKNOWLEDGMENTS}

Work on chemokines and cytokines in murine malaria models is funded by the Deutsche Forschungsgemeinschaft (KA 3347/4-1) and partly by the Max Planck Society. 


\section{REFERENCES}

Adams, Y., Kuhnrae, P., Higgins, M. K., Ghumra, A., and Rowe, J. A. (2014). Rosetting Plasmodium falciparum-infected erythrocytes bind to human brain microvascular endothelial cells in vitro, demonstrating a dual adhesion phenotype mediated by distinct $P$. falciparum erythrocyte membrane protein 1 domains. Infect. Immun. 82, 949-959. doi: 10.1128/IAI.01233-13

Anstey, N. M., Russell, B., Yeo, T. W., and Price, R. N. (2009). The pathophysiology of vivax malaria. Trends Parasitol. 25, 220-227. doi: 10.1016/j.pt.2009.02.003

Armah, H. B., Wilson, N. O., Sarfo, B. Y., Powell, M. D., Bond, V. C., Anderson, W., et al. (2007). Cerebrospinal fluid and serum biomarkers of cerebral malaria mortality in Ghanaian children. Malar. J. 6:147. doi: 10.1186/1475-2875-6-147

Bakmiwewa, S. M., Weiser, S., Grey, M., Heng, B., Guillemin, G. J., Ball, H. J., et al. (2016). Synergistic induction of CXCL10 by interferon-gamma and lymphotoxin-alpha in astrocytes: possible role in cerebral malaria. Cytokine 78, 79-86. doi: 10.1016/j.cyto.2015.11.024

Barker, K. R., Lu, Z., Kim, H., Zheng, Y., Chen, J., Conroy, A. L., et al. (2017). miR-155 modifies inflammation, endothelial activation and bloodbrain barrier dysfunction in cerebral malaria. Mol. Med. 23, 24-33. doi: 10.2119/molmed.2016.00139

Bate, C. A., and Kwiatkowski, D. P. (1994). Stimulators of tumour necrosis factor production released by damaged erythrocytes. Immunology 83, 256-261.

Bauer, P. R., Van Der Heyde, H. C., Sun, G., Specian, R. D., and Granger, D. N. (2002). Regulation of endothelial cell adhesion molecule expression in an experimental model of cerebral malaria. Microcirculation 9, 463-470. doi: 10.1038/sj.mn.7800159

Beare, N. A., Harding, S. P., Taylor, T. E., Lewallen, S., and Molyneux, M. E. (2009). Perfusion abnormalities in children with cerebral malaria and malarial retinopathy. J. Infect. Dis. 199, 263-271. doi: 10.1086/595735

Beare, N. A., Taylor, T. E., Harding, S. P., Lewallen, S., and Molyneux, M. E. (2006). Malarial retinopathy: a newly established diagnostic sign in severe malaria. Am. J. Trop. Med. Hyg. 75, 790-797. doi: 10.4269/ajtmh.2006.75.790

Beeson, J. G., Drew, D. R., Boyle, M. J., Feng, G., Fowkes, F. J., and Richards, J. S. (2016). Merozoite surface proteins in red blood cell invasion, immunity and vaccines against malaria. FEMS Microbiol. Rev. 40, 343-372. doi: 10.1093/femsre/fuw001

Belnoue, E., Costa, F. T., Vigario, A. M., Voza, T., Gonnet, F., Landau, I., et al. (2003). Chemokine receptor CCR2 is not essential for the development of experimental cerebral malaria. Infect. Immun. 71, 3648-3651. doi: 10.1128/IAI.71.6.3648-3651.2003

Bernabeu, M., Danziger, S. A., Avril, M., Vaz, M., Babar, P. H., Brazier, A. J., et al. (2016). Severe adult malaria is associated with specific PfEMP1 adhesion types and high parasite biomass. Proc. Natl. Acad. Sci. U.S.A. 113, E3270-E3279. doi: $10.1073 /$ pnas. 1524294113

Bernabeu, M., and Smith, J.D. (2017). EPCR and malaria severity: the center of a perfect storm. Trends Parasitol. 33, 295-308. doi: 10.1016/j.pt.2016.11.004

Bozza, F. A., Salluh, J. I., Japiassu, A. M., Soares, M., Assis, E. F., Gomes, R. N., et al. (2007). Cytokine profiles as markers of disease severity in sepsis: a multiplex analysis. Crit. Care 11, R49. doi: 10.1186/cc5783

Brown, H., Hien, T. T., Day, N., Mai, N. T., Chuong, L. V., Chau, T. T., et al. (1999). Evidence of blood-brain barrier dysfunction in human cerebral malaria. Neuropathol. Appl. Neurobiol. 25, 331-340. doi: 10.1046/j.1365-2990.1999.00188.x

Brown, H., Rogerson, S., Taylor, T., Tembo, M., Mwenechanya, J., Molyneux, M., et al. (2001). Blood-brain barrier function in cerebral malaria in Malawian children. Am. J. Trop. Med. Hyg. 64, 207-213. doi: 10.4269/ajtmh.2001.64.207

Bujila, I., Schwarzer, E., Skorokhod, O., Weidner, J. M., Troye-Blomberg, M., and Ostlund Farrants, A. K. (2016). Malaria-derived hemozoin exerts early modulatory effects on the phenotype and maturation of human dendritic cells. Cell. Microbiol. 18, 413-423. doi: 10.1111/cmi.12521

Campanella, G. S., Tager, A. M., El Khoury, J. K., Thomas, S. Y., Abrazinski, T. A., Manice, L. A., et al. (2008). Chemokine receptor CXCR3 and its ligands CXCL9 and CXCL10 are required for the development of murine cerebral malaria. Proc. Natl. Acad. Sci. U.S.A. 105, 4814-4819. doi: 10.1073/pnas.0801544105

Campos, F. M., Franklin, B. S., Teixeira-Carvalho, A., Filho, A. L., De Paula, S. C., Fontes, C. J., et al. (2010). Augmented plasma microparticles during acute Plasmodium vivax infection. Malar. J. 9:327. doi: 10.1186/1475-2875-9-327
Capuccini, B., Lin, J., Talavera-Lopez, C., Khan, S. M., Sodenkamp, J., Spaccapelo, R., et al. (2016). Transcriptomic profiling of microglia reveals signatures of cell activation and immune response, during experimental cerebral malaria. Sci. Rep. 6:39258. doi: 10.1038/srep39258

Cavender, D. E., Edelbaum, D., and Ziff, M. (1989). Endothelial cell activation induced by tumor necrosis factor and lymphotoxin. Am. J. Pathol. 134, 551-560.

Chakravorty, S. J., Carret, C., Nash, G. B., Ivens, A., Szestak, T., and Craig, A. G. (2007). Altered phenotype and gene transcription in endothelial cells, induced by Plasmodium falciparum-infected red blood cells: pathogenic or protective? Int. J. Parasitol. 37, 975-987. doi: 10.1016/j.ijpara.2007.02.006

Chen, Q., Schlichtherle, M., and Wahlgren, M. (2000). Molecular aspects of severe malaria. Clin. Microbiol. Rev. 13, 439-450. doi: 10.1128/CMR.13.3.439-450.2000

Clark, I. A., Alleva, L. M., Mills, A. C., and Cowden, W. B. (2004). Pathogenesis of malaria and clinically similar conditions. Clin. Microbiol. Rev. 17, 509-539. doi: 10.1128/CMR.17.3.509-539.2004

Clark, I. A., Budd, A. C., Alleva, L. M., and Cowden, W. B. (2006). Human malarial disease: a consequence of inflammatory cytokine release. Malar. J. 5:85. doi: 10.1186/1475-2875-5-85

Clark, I. A., and Rockett, K. A. (1994). The cytokine theory of human cerebral malaria. Parasitol. Today 10, 410-412. doi: 10.1016/0169-4758(94)90237-2

Clark, I.A., and Vissel, B. (2017). The meteorology of cytokine storms, and the clinical usefulness of this knowledge. Semin. Immunopathol. 39, 505-516. doi: 10.1007/s00281-017-0628-y

Coban, C., Ishii, K. J., Kawai, T., Hemmi, H., Sato, S., Uematsu, S., et al. (2005). Toll-like receptor 9 mediates innate immune activation by the malaria pigment hemozoin. J. Exp. Med. 201, 19-25. doi: 10.1084/jem.20041836

Combes, V., El-Assaad, F., Faille, D., Jambou, R., Hunt, N. H., and Grau, G. E. (2010). Microvesiculation and cell interactions at the brain-endothelial interface in cerebral malaria pathogenesis. Prog. Neurobiol. 91, 140-151. doi: 10.1016/j.pneurobio.2010.01.007

Couper, K. N., Barnes, T., Hafalla, J. C., Combes, V., Ryffel, B., Secher, T., et al. (2010). Parasite-derived plasma microparticles contribute significantly to malaria infection-induced inflammation through potent macrophage stimulation. PLoS Pathog. 6:e1000744. doi: 10.1371/journal.ppat.1000744

Craig, A. G., Grau, G. E., Janse, C., Kazura, J. W., Milner, D., Barnwell, J. W., et al. (2012). The role of animal models for research on severe malaria. PLoS Pathog. 8:e1002401. doi: 10.1371/journal.ppat.1002401

Cui, L., Mharakurwa, S., Ndiaye, D., Rathod, P. K., and Rosenthal, P. J. (2015). Antimalarial drug resistance: literature review and activities and findings of the ICEMR network. Am. J. Trop. Med. Hyg. 93, 57-68. doi: 10.4269/ajtmh.15-0007

De Backer, D., Creteur, J., Preiser, J. C., Dubois, M. J., and Vincent, J. L. (2002). Microvascular blood flow is altered in patients with sepsis. Am. J. Respir. Crit. Care Med. 166, 98-104. doi: 10.1164/rccm.200109-016OC

de Souza, J. B., and Riley, E. M. (2002). Cerebral malaria: the contribution of studies in animal models to our understanding of immunopathogenesis. Microbes Infect. 4, 291-300. doi: 10.1016/S1286-4579(02)01541-1

Di Perri, G., Di Perri, I. G., Monteiro, G. B., Bonora, S., Hennig, C., Cassatella, M., et al. (1995). Pentoxifylline as a supportive agent in the treatment of cerebral malaria in children. J. Infect. Dis. 171, 1317-1322. doi: 10.1093/infdis/171.5.1317

Dondorp, A. M., Fanello, C. I., Hendriksen, I. C., Gomes, E., Seni, A., Chhaganlal, K. D., et al. (2010). Artesunate versus quinine in the treatment of severe falciparum malaria in African children (AQUAMAT): an open-label, randomised trial. Lancet 376, 1647-1657. doi: 10.1016/S0140-6736(10)61924-1

Dondorp, A. M., Ince, C., Charunwatthana, P., Hanson, J., Van Kuijen, A., Faiz, M. A., et al. (2008). Direct in vivo assessment of microcirculatory dysfunction in severe falciparum malaria. J. Infect. Dis. 197, 79-84. doi: 10.1086/523762

Dondorp, A. M., Pongponratn, E., and White, N. J. (2004). Reduced microcirculatory flow in severe falciparum malaria: pathophysiology and electron-microscopic pathology. Acta Trop. 89, 309-317. doi: 10.1016/j.actatropica.2003.10.004

Dondorp, A., Nosten, F., Stepniewska, K., Day, N., White, N., and South East Asian Quinine Artesunate Malaria Trial, G. (2005). Artesunate versus quinine for treatment of severe falciparum malaria: a randomised trial. Lancet 366, 717-725. doi: 10.1016/S0140-6736(05)67176-0 
Dong, Y., and Benveniste, E. N. (2001). Immune function of astrocytes. Glia 36, 180-190. doi: 10.1002/glia.1107

Engwerda, C. R., Mynott, T. L., Sawhney, S., De Souza, J. B., Bickle, Q. D., and Kaye, P. M. (2002). Locally up-regulated lymphotoxin alpha, not systemic tumor necrosis factor alpha, is the principle mediator of murine cerebral malaria. $J$. Exp. Med. 195, 1371-1377. doi: 10.1084/jem.20020128

Eriksson, E. M., Sampaio, N. G., and Schofield, L. (2013). Toll-like Receptors and malaria: sensing and susceptibility. J. Trop. Dis. 2:126. doi: 10.4172/2329-891X.1000126

Evans, S. S., Repasky, E. A., and Fisher, D. T. (2015). Fever and the thermal regulation of immunity: the immune system feels the heat. Nat. Rev. Immunol. 15, 335-349. doi: 10.1038/nri3843

Favre, N., Da Laperousaz, C., Ryffel, B., Weiss, N. A., Imhof, B. A., Rudin, W., et al. (1999). Role of ICAM-1 (CD54) in the development of murine cerebral malaria. Microbes Infect. 1, 961-968. doi: 10.1016/S1286-4579(99)80513-9

Francis, S. E., Sullivan, D. J. Jr., and Goldberg, D.E. (1997). Hemoglobin metabolism in the malaria parasite Plasmodium falciparum. Annu. Rev. Microbiol. 51, 97-123. doi: 10.1146/annurev.micro.51.1.97

Gazzinelli, R. T., Kalantari, P., Fitzgerald, K. A., and Golenbock, D. T. (2014). Innate sensing of malaria parasites. Nat. Rev. Immunol. 14, 744-757. doi: $10.1038 /$ nri3742

Gilson, P. R., and Crabb, B. S. (2009). Morphology and kinetics of the three distinct phases of red blood cell invasion by Plasmodium falciparum merozoites. Int. J. Parasitol. 39, 91-96. doi: 10.1016/j.jpara.2008.09.007

Gowda, D. C. (2007). TLR-mediated cell signaling by malaria GPIs. Trends Parasitol. 23, 596-604. doi: 10.1016/j.pt.2007.09.003

Grau, G. E., Pointaire, P., Piguet, P. F., Vesin, C., Rosen, H., Stamenkovic, I., et al. (1991). Late administration of monoclonal antibody to leukocyte functionantigen 1 abrogates incipient murine cerebral malaria. Eur. J. Immunol. 21, 2265-2267. doi: $10.1002 /$ eji.1830210939

Griffith, J. W., Sokol, C. L., and Luster, A. D. (2014). Chemokines and chemokine receptors: positioning cells for host defense and immunity. Annu. Rev. Immunol. 32, 659-702. doi: 10.1146/annurev-immunol-032713-120145

Hafalla, J. C., Silvie, O., and Matuschewski, K. (2011). Cell biology and immunology of malaria. Immunol. Rev. 240, 297-316. doi: 10.1111/j.1600-065X.2010.00988.x

Haldar, K., Murphy, S. C., Milner, D. A., and Taylor, T. E. (2007). Malaria: mechanisms of erythrocytic infection and pathological correlates of severe disease. Annu. Rev. Pathol. 2, 217-249. doi: 10.1146/annurev.pathol.2.010506.091913

Handunnetti, S. M., David, P. H., Perera, K. L., and Mendis, K. N. (1989). Uninfected erythrocytes form "rosettes" around Plasmodium falciparum infected erythrocytes. Am. J. Trop. Med. Hyg. 40, 115-118. doi: 10.4269/ajtmh.1989.40.115

Hansen, D. S., Bernard, N. J., Nie, C. Q., and Schofield, L. (2007). NK cells stimulate recruitment of CXCR3 $+\mathrm{T}$ cells to the brain during Plasmodium berghei-mediated cerebral malaria. J. Immunol. 178, 5779-5788. doi: 10.4049/jimmunol.178.9.5779

Haque, A., Best, S. E., Unosson, K., Amante, F. H., De Labastida, F., Anstey, N. M., et al. (2011). Granzyme B expression by CD8+ T cells is required for the development of experimental cerebral malaria. J. Immunol. 186, 6148-6156. doi: 10.4049/jimmunol.1003955

Hermsen, C. C., Konijnenberg, Y., Mulder, L., Loe, C., Van Deuren, M., Van Der Meer, J. W., et al. (2003). Circulating concentrations of soluble granzyme $\mathrm{A}$ and $\mathrm{B}$ increase during natural and experimental Plasmodium falciparum infections. Clin. Exp. Immunol. 132, 467-472. doi: 10.1046/j.1365-2249.2003.02 160.x

Hol, J., Wilhelmsen, L., and Haraldsen, G. (2010). The murine IL-8 homologues KC, MIP-2, and LIX are found in endothelial cytoplasmic granules but not in Weibel-Palade bodies. J. Leukoc. Biol. 87, 501-508. doi: 10.1189/jlb .0809532

Howland, S. W., Claser, C., Poh, C. M., Gun, S. Y., and Renia, L. (2015a). Pathogenic CD8+ T cells in experimental cerebral malaria. Semin. Immunopathol. 37, 221-231. doi: 10.1007/s00281-015-0476-6

Howland, S. W., Poh, C. M., and Renia, L. (2015b). Activated brain endothelial cells cross-present malaria antigen. PLoS Pathog. 11:e1004963. doi: 10.1371/journal.ppat.1004963

Huggins, M. A., Johnson, H. L., Jin, F., N'Songo A., Hanson, L. M., Lafrance, S. J., et al. (2017). Perforin expression by CD8 T cells Is sufficient to cause fatal brain edema during experimental cerebral malaria. Infect. Immun. 85, e00985-e00916. doi: 10.1128/IAI.00985-16

Hunt, N. H., Golenser, J., Chan-Ling, T., Parekh, S., Rae, C., Potter, S., et al. (2006). Immunopathogenesis of cerebral malaria. Int. J. Parasitol. 36, 569-582. doi: 10.1016/j.ijpara.2006.02.016

Hunt, N. H., and Grau, G. E. (2003). Cytokines: accelerators and brakes in the pathogenesis of cerebral malaria. Trends Immunol. 24, 491-499. doi: 10.1016/S1471-4906(03)00229-1

Idro, R., Marsh, K., John, C. C., and Newton, C. R. (2010). Cerebral malaria: mechanisms of brain injury and strategies for improved neurocognitive outcome. Pediatr. Res. 68, 267-274. doi: 10.1203/PDR.0b013e3181eee738

Ioannidis, L. J., Nie, C. Q., and Hansen, D. S. (2014). The role of chemokines in severe malaria: more than meets the eye. Parasitology 141, 602-613. doi: $10.1017 /$ S0031182013001984

Ioannidis, L. J., Nie, C. Q., Ly, A., Ryg-Cornejo, V., Chiu, C. Y., and Hansen, D. S. (2016). Monocyte- and neutrophil-derived CXCL10 impairs efficient control of blood-stage malaria infection and promotes severe disease. J. Immunol. 196, 1227-1238. doi: 10.4049/jimmunol.1501562

Jain, V., Armah, H. B., Tongren, J. E., Ned, R. M., Wilson, N. O., Crawford, S., et al. (2008). Plasma IP-10, apoptotic and angiogenic factors associated with fatal cerebral malaria in India. Malar. J. 7:83. doi: 10.1186/1475-2875-7-83

Jambou, R., Combes, V., Jambou, M. J., Weksler, B. B., Couraud, P. O., and Grau, G. E. (2010). Plasmodium falciparum adhesion on human brain microvascular endothelial cells involves transmigration-like cup formation and induces opening of intercellular junctions. PLoS Pathog. 6:e1001021. doi: 10.1371/journal.ppat.1001021

John, C. C., Bangirana, P., Byarugaba, J., Opoka, R. O., Idro, R., Jurek, A. M., et al. (2008a). Cerebral malaria in children is associated with long-term cognitive impairment. Pediatrics 122, e92-e99. doi: 10.1542/peds.2007-3709

John, C. C., Panoskaltsis-Mortari, A., Opoka, R. O., Park, G. S., Orchard, P. J., Jurek, A. M., et al. (2008b). Cerebrospinal fluid cytokine levels and cognitive impairment in cerebral malaria. Am. J. Trop. Med. Hyg. 78, 198-205. doi: $10.4269 /$ ajtmh.2008.78.198

Kalantari, P., Deoliveira, R. B., Chan, J., Corbett, Y., Rathinam, V., Stutz, A., et al. (2014). Dual engagement of the NLRP3 and AIM2 inflammasomes by plasmodium-derived hemozoin and DNA during malaria. Cell Rep. 6, 196-210. doi: 10.1016/j.celrep.2013.12.014

Karin, N., and Wildbaum, G. (2015). The role of chemokines in shaping the balance between $\mathrm{CD} 4(+) \mathrm{T}$ cell subsets and its therapeutic implications in autoimmune and cancer diseases. Front. Immunol. 6:609. doi: 10.3389/fimmu.2015.00609

Karunaweera, N. D., Grau, G. E., Gamage, P., Carter, R., and Mendis, K. N. (1992). Dynamics of fever and serum levels of tumor necrosis factor are closely associated during clinical paroxysms in Plasmodium vivax malaria. Proc. Natl. Acad. Sci. U.S.A. 89, 3200-3203. doi: 10.1073/pnas.89.8.3200

Kochar, D. K., Das, A., Kochar, S. K., Saxena, V., Sirohi, P., Garg, S., et al. (2009). Severe Plasmodium vivax malaria: a report on serial cases from Bikaner in northwestern India. Am. J. Trop. Med. Hyg. 80, 194-198. doi: 10.3410/f.1161230.621714

Kordes, M., Matuschewski, K., and Hafalla, J.C. (2011). Caspase-1 activation of interleukin-1beta (IL-1beta) and IL-18 is dispensable for induction of experimental cerebral malaria. Infect. Immun. 79, 3633-3641. doi: 10.1128/IAL.05459-11

Krishnegowda, G., Hajjar, A. M., Zhu, J., Douglass, E. J., Uematsu, S., Akira, S., et al. (2005). Induction of proinflammatory responses in macrophages by the glycosylphosphatidylinositols of Plasmodium falciparum: cell signaling receptors, glycosylphosphatidylinositol (GPI) structural requirement, and regulation of GPI activity. J. Biol. Chem. 280, 8606-8616. doi: 10.1074/jbc.M413541200

Kwiatkowski, D., Cannon, J. G., Manogue, K. R., Cerami, A., Dinarello, C. A., and Greenwood, B. M. (1989). Tumour necrosis factor production in Falciparum malaria and its association with schizont rupture. Clin. Exp. Immunol. 77, 361-366.

Kwiatkowski, D., Hill, A. V., Sambou, I., Twumasi, P., Castracane, J., Manogue, K. R., et al. (1990). TNF concentration in fatal cerebral, non-fatal cerebral, and uncomplicated Plasmodium falciparum malaria. Lancet 336, 1201-1204. doi: 10.1016/0140-6736(90)92827-5

Langhorne, J., Ndungu, F. M., Sponaas, A. M., and Marsh, K. (2008). Immunity to malaria: more questions than answers. Nat. Immunol. 9, 725-732. doi: 10.1038/ni.f.205 
Lennartz, F., Adams, Y., Bengtsson, A., Olsen, R. W., Turner, L., Ndam, N. T., et al. (2017). Structure-guided identification of a family of dual receptor-binding PfEMP1 that is associated with cerebral malaria. Cell Host Microbe 21, 403-414. doi: 10.1016/j.chom.2017.02.009

Lepenies, B., Cramer, J. P., Burchard, G. D., Wagner, H., Kirschning, C. J., and Jacobs, T. (2008). Induction of experimental cerebral malaria is independent of TLR2/4/9. Med. Microbiol. Immunol. 197, 39-44. doi: 10.1007/s00430-007-0057-y

Liehl, P., and Mota, M. M. (2012). Innate recognition of malarial parasites by mammalian hosts. Int. J. Parasitol. 42, 557-566. doi: 10.1016/j.ijpara.2012. 04.006

Liehl, P., Zuzarte-Luis, V., Chan, J., Zillinger, T., Baptista, F., Carapau, D., et al. (2014). Host-cell sensors for Plasmodium activate innate immunity against liver-stage infection. Nat. Med. 20, 47-53. doi: 10.1038/nm.3424

Lopez-Ramirez, M. A., Wu, D., Pryce, G., Simpson, J. E., Reijerkerk, A., King-Robson, J., et al. (2014). MicroRNA-155 negatively affects bloodbrain barrier function during neuroinflammation. FASEB J. 28, 2551-2565. doi: 10.1096/fj.13-248880

Lucas, R., Juillard, P., Decoster, E., Redard, M., Burger, D., Donati, Y., et al. (1997). Crucial role of tumor necrosis factor (TNF) receptor 2 and membranebound TNF in experimental cerebral malaria. Eur. J. Immunol. 27, 1719-1725. doi: 10.1002/eji.1830270719

Mai, J., Virtue, A., Shen, J., Wang, H., and Yang, X. F. (2013). An evolving new paradigm: endothelial cells-conditional innate immune cells. J. Hematol. Oncol. 6:61. doi: 10.1186/1756-8722-6-61

Mandala, W. L., Msefula, C. L., Gondwe, E. N., Drayson, M. T., Molyneux, M. E., and Maclennan, C. A. (2017). Cytokine profiles in Malawian children presenting with uncomplicated malaria, severe malarial anemia and cerebral malaria. Clin. Vaccine Immunol. 24:e00533-16. doi: 10.1128/CVI.00533-16

Mantel, P. Y., Hjelmqvist, D., Walch, M., Kharoubi-Hess, S., Nilsson, S., Ravel, D., et al. (2016). Infected erythrocyte-derived extracellular vesicles alter vascular function via regulatory Ago2-miRNA complexes in malaria. Nat. Commun. 7:12727. doi: $10.1038 /$ ncomms 12727

Mantel, P. Y., Hoang, A. N., Goldowitz, I., Potashnikova, D., Hamza, B., Vorobjev, I., et al. (2013). Malaria-infected erythrocyte-derived microvesicles mediate cellular communication within the parasite population and with the host immune system. Cell Host Microbe 13, 521-534. doi: 10.1016/j.chom.2013.04.009

McCutchan, T. F., Dame, J. B., Miller, L. H., and Barnwell, J. (1984). Evolutionary relatedness of Plasmodium species as determined by the structure of DNA. Science 225, 808-811. doi: 10.1126/science.6382604

McGilvray, I. D., Serghides, L., Kapus, A., Rotstein, O. D., and Kain, K. C. (2000). Nonopsonic monocyte/macrophage phagocytosis of Plasmodium falciparumparasitized erythrocytes: a role for CD36 in malarial clearance. Blood 96, 3231-3240. Available online at: http://www.bloodjournal.org/content/96/9/ 3231

Medana, I. M., Chaudhri, G., Chan-Ling, T., and Hunt, N. H. (2001). Central nervous system in cerebral malaria: 'Innocent bystander' or active participant in the induction of immunopathology? Immunol. Cell Biol. 79, 101-120. doi: 10.1046/j.1440-1711.2001.00995.x

Medana, I. M., and Turner, G. D. (2006). Human cerebral malaria and the bloodbrain barrier. Int. J. Parasitol. 36, 555-568. doi: 10.1016/j.ijpara.2006.02.004

Medana, I. M., and Turner, G. D. (2007). Plasmodium falciparum and the blood-brain barrier-contacts and consequences. J. Infect. Dis. 195, 921-923. doi: $10.1086 / 512089$

Miller, J. L., Sack, B. K., Baldwin, M., Vaughan, A. M., and Kappe, S. H. (2014). Interferon-mediated innate immune responses against malaria parasite liver stages. Cell Rep. 7, 436-447. doi: 10.1016/j.celrep.2014.03.018

Miller, L. H., Baruch, D. I., Marsh, K., and Doumbo, O. K. (2002). The pathogenic basis of malaria. Nature 415, 673-679. doi: 10.1038/415673a

Milner, D. A. Jr., Lee, J. J., Frantzreb, C., Whitten, R. O., Kamiza, S., Carr, R. A., et al. (2015). Quantitative assessment of multiorgan sequestration of parasites in fatal pediatric cerebral malaria. J. Infect. Dis. 212, 1317-1321. doi: 10.1093/infdis/jiv205

Milner, D. A. Jr., Whitten, R. O., Kamiza, S., Carr, R., Liomba, G., Dzamalala, C., et al. (2014). The systemic pathology of cerebral malaria in African children. Front. Cell. Infect. Microbiol. 4:104. doi: 10.3389/fcimb.2014.00104

Miu, J., Mitchell, A. J., Muller, M., Carter, S. L., Manders, P. M., Mcquillan, J. A., et al. (2008). Chemokine gene expression during fatal murine cerebral malaria and protection due to CXCR3 deficiency. J. Immunol. 180, 1217-1230. doi: 10.4049/jimmunol.180.2.1217

Nantakomol, D., Dondorp, A. M., Krudsood, S., Udomsangpetch, R., Pattanapanyasat, K., Combes, V., et al. (2011). Circulating red cellderived microparticles in human malaria. J. Infect. Dis. 203, 700-706. doi: 10.1093/infdis/jiq104

Nie, C. Q., Bernard, N. J., Norman, M. U., Amante, F. H., Lundie, R. J., Crabb, B. S., et al. (2009). IP-10-mediated T cell homing promotes cerebral inflammation over splenic immunity to malaria infection. PLoS Pathog. 5:e1000369. doi: 10.1371/journal.ppat.1000369

Oakley, M. S., Gerald, N., Mccutchan, T. F., Aravind, L., and Kumar, S. (2011). Clinical and molecular aspects of malaria fever. Trends Parasitol. 27, 442-449. doi: 10.1016/j.pt.2011.06.004

Obermeier, B., Daneman, R., and Ransohoff, R. M. (2013). Development, maintenance and disruption of the blood-brain barrier. Nat. Med. 19, 1584-1596. doi: 10.1038/nm.3407

Olivier, M., Van Den Ham, K., Shio, M. T., Kassa, F. A., and Fougeray, S. (2014). Malarial pigment hemozoin and the innate inflammatory response. Front. Immunol. 5:25. doi: 10.3389/fimmu.2014.00025

Olotu, A., Fegan, G., Wambua, J., Nyangweso, G., Leach, A., Lievens, M., et al. (2016). Seven-Year efficacy of RTS,S/AS01 malaria vaccine among young African children. N. Engl. J. Med. 374, 2519-2529. doi: 10.1056/NEJMoa1515257

Pain, A., Ferguson, D. J., Kai, O., Urban, B. C., Lowe, B., Marsh, K., et al. (2001). Platelet-mediated clumping of Plasmodium falciparum-infected erythrocytes is a common adhesive phenotype and is associated with severe malaria. Proc. Natl. Acad. Sci. U.S.A. 98, 1805-1810. doi: 10.1073/pnas.98.4.1805

Palomo, J., Fauconnier, M., Coquard, L., Gilles, M., Meme, S., Szeremeta, F., et al. (2013). Type I interferons contribute to experimental cerebral malaria development in response to sporozoite or blood-stage Plasmodium berghei ANKA. Eur. J. Immunol. 43, 2683-2695. doi: 10.1002/eji.2013 43327

Parroche, P., Lauw, F. N., Goutagny, N., Latz, E., Monks, B. G., Visintin, A., et al. (2007). Malaria hemozoin is immunologically inert but radically enhances innate responses by presenting malaria DNA to Toll-like receptor 9. Proc. Natl. Acad. Sci. U.S.A. 104, 1919-1924. doi: 10.1073/pnas.06087 45104

Pasloske, B. L., and Howard, R. J. (1994). Malaria, the red cell, and the endothelium. Annu. Rev. Med. 45, 283-295. doi: 10.1146/annurev.med.45.1.283

Pober, J. S., and Cotran, R. S. (1990). Cytokines and endothelial cell biology. Physiol. Rev. 70, 427-451.

Pober, J. S., and Sessa, W. C. (2007). Evolving functions of endothelial cells in inflammation. Nat. Rev. Immunol. 7, 803-815. doi: 10.1038/nri2171

Ponsford, M. J., Medana, I. M., Prapansilp, P., Hien, T. T., Lee, S. J., Dondorp, A. M., et al. (2012). Sequestration and microvascular congestion are associated with coma in human cerebral malaria. J. Infect. Dis. 205, 663-671. doi: 10.1093/infdis/jir812

Prakash, D., Fesel, C., Jain, R., Cazenave, P. A., Mishra, G. C., and Pied, S. (2006). Clusters of cytokines determine malaria severity in Plasmodium falciparuminfected patients from endemic areas of central India. J. Infect. Dis. 194, 198-207. doi: 10.1086/504720

Renia, L., Howland, S. W., Claser, C., Charlotte Gruner, A., Suwanarusk, R., Hui Teo, T., et al. (2012). Cerebral malaria: mysteries at the blood-brain barrier. Virulence 3, 193-201. doi: 10.4161/viru.19013

Riley, E. M., Couper, K. N., Helmby, H., Hafalla, J. C., De Souza, J. B., Langhorne, J., et al. (2010). Neuropathogenesis of human and murine malaria. Trends Parasitol. 26, 277-278. doi: 10.1016/j.pt.2010.03.002

Rowe, J. A., Claessens, A., Corrigan, R. A., and Arman, M. (2009). Adhesion of Plasmodium falciparum-infected erythrocytes to human cells: molecular mechanisms and therapeutic implications. Expert Rev. Mol. Med. 11:e16. doi: 10.1017/S1462399409001082

Sahu, P. K., Satpathi, S., Behera, P. K., Mishra, S. K., Mohanty, S., and Wassmer, S. C. (2015). Pathogenesis of cerebral malaria: new diagnostic tools, biomarkers, and therapeutic approaches. Front. Cell. Infect. Microbiol. 5:75. doi: $10.3389 /$ fcimb. 2015.00075

Sahu, U., Sahoo, P. K., Kar, S. K., Mohapatra, B. N., and Ranjit, M. (2013). Association of TNF level with production of circulating cellular microparticles during clinical manifestation of human cerebral malaria. Hum. Immunol. 74, 713-721. doi: 10.1016/j.humimm.2013.02.006 
Schofield, L., and Grau, G. E. (2005). Immunological processes in malaria pathogenesis. Nat. Rev. Immunol. 5, 722-735. doi: 10.1038/nri1686

Schofield, L., and Hackett, F. (1993). Signal transduction in host cells by a glycosylphosphatidylinositol toxin of malaria parasites. J. Exp. Med. 177, 145-153. doi: 10.1084/jem.177.1.145

Shabani, E., Ouma, B. J., Idro, R., Bangirana, P., Opoka, R. O., Park, G. S., et al. (2017). Elevated cerebrospinal fluid tumour necrosis factor is associated with acute and long-term neurocognitive impairment in cerebral malaria. Parasite Immunol. 39:e12438. doi: 10.1111/pim.12438

Sharma, S., Deoliveira, R. B., Kalantari, P., Parroche, P., Goutagny, N., Jiang, Z., et al. (2011). Innate immune recognition of an AT-rich stem-loop DNA motif in the Plasmodium falciparum genome. Immunity 35, 194-207. doi: 10.1016/j.immuni.2011.05.016

Shrivastava, S. K., Dalko, E., Delcroix-Genete, D., Herbert, F., Cazenave, P. A., and Pied, S. (2017). Uptake of parasite-derived vesicles by astrocytes and microglial phagocytosis of infected erythrocytes may drive neuroinflammation in cerebral malaria. Glia 65, 75-92. doi: 10.1002/glia.23075

Sigala, P. A., and Goldberg, D. E. (2014). The peculiarities and paradoxes of Plasmodium heme metabolism. Annu. Rev. Microbiol. 68, 259-278. doi: 10.1146/annurev-micro-091313-103537

Smith, J. D., Rowe, J. A., Higgins, M. K., and Lavstsen, T. (2013). Malaria's deadly grip: cytoadhesion of Plasmodium falciparum-infected erythrocytes. Cell. Microbiol. 15, 1976-1983. doi: 10.1111/cmi.12183

Song, L., and Pachter, J. S. (2004). Monocyte chemoattractant protein-1 alters expression of tight junction-associated proteins in brain microvascular endothelial cells. Microvasc. Res. 67, 78-89. doi: 10.1016/j.mvr.2003.07.001

Srivastava, K., Cockburn, I. A., Swaim, A., Thompson, L. E., Tripathi, A., Fletcher, C. A., et al. (2008). Platelet factor 4 mediates inflammation in experimental cerebral malaria. Cell Host Microbe 4, 179-187. doi: 10.1016/j.chom.2008.07.003

Stamatovic, S. M., Keep, R. F., Kunkel, S. L., and Andjelkovic, A. V. (2003). Potential role of MCP-1 in endothelial cell tight junction 'opening': signaling via Rho and Rho kinase. J. Cell Sci. 116, 4615-4628. doi: 10.1242/jcs. 00755

Stevenson, M. M., and Riley, E. M. (2004). Innate immunity to malaria. Nat. Rev. Immunol. 4, 169-180. doi: 10.1038/nri1311

Storm, J., and Craig, A. G. (2014). Pathogenesis of cerebral malariainflammation and cytoadherence. Front. Cell. Infect. Microbiol. 4:100. doi: $10.3389 /$ fcimb. 2014.00100

Strack, A., Schlüter, D., Asensio, V.C., Campbell, I. L., and Deckert, M. (2002). Regulation of the kinetics of intracerebral chemokine gene expression in murine Toxoplasma encephalitis: impact of host genetic factors. Glia 40, 372-377. doi: 10.1002/glia.10104

Tachado, S. D., Gerold, P., Mcconville, M. J., Baldwin, T., Quilici, D., Schwarz, R. T., et al. (1996). Glycosylphosphatidylinositol toxin of Plasmodium induces nitric oxide synthase expression in macrophages and vascular endothelial cells by a protein tyrosine kinase-dependent and protein kinase C-dependent signaling pathway. J. Immunol. 156, 1897-1907.

Takeuchi, O., and Akira, S. (2010). Pattern recognition receptors and inflammation. Cell 140, 805-820. doi: 10.1016/j.cell.2010.01.022

Tchinda, V. H., Tadem, A. D., Tako, E. A., Tene, G., Fogako, J., Nyonglema, P., et al. (2007). Severe malaria in Cameroonian children: correlation between plasma levels of three soluble inducible adhesion molecules and TNF-alpha. Acta Trop. 102, 20-28. doi: 10.1016/j.actatropica.2007.02.011

Thuma, P. E., Van Dijk, J., Bucala, R., Debebe, Z., Nekhai, S., Kuddo, T., et al. (2011). Distinct clinical and immunologic profiles in severe malarial anemia and cerebral malaria in Zambia. J. Infect. Dis. 203, 211-219. doi: 10.1093/infdis/jiq041

Tiberti, N., Latham, S. L., Bush, S., Cohen, A., Opoka, R. O., John, C. C., et al. (2016). Exploring experimental cerebral malaria pathogenesis through the characterisation of host-derived plasma microparticle protein content. Sci. Rep. 6:37871. doi: 10.1038/srep37871

Togbe, D., Schofield, L., Grau, G. E., Schnyder, B., Boissay, V., Charron, S., et al. (2007). Murine cerebral malaria development is independent of toll-like receptor signaling. Am. J. Pathol. 170, 1640-1648. doi: 10.2353/ajpath.2007.060889

Tripathi, A. K., Sha, W., Shulaev, V., Stins, M. F., and Sullivan, D. J. Jr., (2009). Plasmodium falciparum-infected erythrocytes induce NF-kappaB regulated inflammatory pathways in human cerebral endothelium. Blood 114, 4243-4252. doi: 10.1182/blood-2009-06-226415

Tripathi, A. K., Sullivan, D. J., and Stins, M. F. (2006). Plasmodium falciparuminfected erythrocytes increase intercellular adhesion molecule 1 expression on brain endothelium through NF-kappaB. Infect. Immun. 74, 3262-3270. doi: 10.1128/IAI.01625-05

Tripathi, A. K., Sullivan, D. J., and Stins, M. F. (2007). Plasmodium falciparuminfected erythrocytes decrease the integrity of human blood-brain barrier endothelial cell monolayers. J. Infect. Dis. 195, 942-950. doi: 10.1086/512083

Turner, G. D., Ly, V. C., Nguyen, T. H., Tran, T. H., Nguyen, H. P., Bethell, D., et al. (1998). Systemic endothelial activation occurs in both mild and severe malaria. Correlating dermal microvascular endothelial cell phenotype and soluble cell adhesion molecules with disease severity. Am. J. Pathol. 152, 1477-1487.

Turner, G. D., Morrison, H., Jones, M., Davis, T. M., Looareesuwan, S., Buley, I. D., et al. (1994). An immunohistochemical study of the pathology of fatal malaria. Evidence for widespread endothelial activation and a potential role for intercellular adhesion molecule-1 in cerebral sequestration. Am. J. Pathol. 145, 1057-1069.

Turner, L., Lavstsen, T., Berger, S. S., Wang, C. W., Petersen, J. E., Avril, M., et al. (2013). Severe malaria is associated with parasite binding to endothelial protein C receptor. Nature 498, 502-505. doi: 10.1038/nature12216

Van den Steen, P. E., Deroost, K., Van Aelst, I., Geurts, N., Martens, E., Struyf, S., et al. (2008). CXCR3 determines strain susceptibility to murine cerebral malaria by mediating $\mathrm{T}$ lymphocyte migration toward IFN-gamma-induced chemokines. Eur. J. Immunol. 38, 1082-1095. doi: 10.1002/eji.200737906

van der Heyde, H. C., Nolan, J., Combes, V., Gramaglia, I., and Grau, G. E. (2006). A unified hypothesis for the genesis of cerebral malaria: sequestration, inflammation and hemostasis leading to microcirculatory dysfunction. Trends Parasitol. 22, 503-508. doi: 10.1016/j.pt.2006.09.002

van Hensbroek, M. B., Palmer, A., Onyiorah, E., Schneider, G., Jaffar, S., Dolan, G., et al. (1996). The effect of a monoclonal antibody to tumor necrosis factor on survival from childhood cerebral malaria. J. Infect. Dis. 174, 1091-1097. doi: 10.1093/infdis/174.5.1091

Viebig, N. K., Wulbrand, U., Forster, R., Andrews, K. T., Lanzer, M., and Knolle, P. A. (2005). Direct activation of human endothelial cells by Plasmodium falciparum-infected erythrocytes. Infect. Immun. 73, 3271-3277. doi: 10.1128/IAI.73.6.3271-3277.2005

Villegas-Mendez, A., Greig, R., Shaw, T. N., De Souza, J. B., Gwyer Findlay, E., Stumhofer, J. S., et al. (2012). IFN-gamma-producing CD4+ T cells promote experimental cerebral malaria by modulating CD8 + T cell accumulation within the brain. J. Immunol. 189, 968-979. doi: 10.4049/jimmunol.1200688

Viola, A., and Luster, A. D. (2008). Chemokines and their receptors: drug targets in immunity and inflammation. Annu. Rev. Pharmacol. Toxicol. 48, 171-197. doi: 10.1146/annurev.pharmtox.48.121806.154841

Wassmer, S. C., and Grau, G. E. (2017). Severe malaria: what's new on the pathogenesis front? Int. J. Parasitol. 47, 145-152. doi: 10.1016/j.ijpara.2016. 08.002

Wassmer, S. C., Moxon, C. A., Taylor, T., Grau, G. E., Molyneux, M. E., and Craig, A. G. (2011). Vascular endothelial cells cultured from patients with cerebral or uncomplicated malaria exhibit differential reactivity to TNF. Cell. Microbiol. 13, 198-209. doi: 10.1111/j.1462-5822.2010.01528.x

WHO (2016). World Malaria Report 2016. Geneva: World Health Organisation.

White, M. T., Verity, R., Griffin, J. T., Asante, K. P., Owusu-Agyei, S., Greenwood, B., et al. (2015). Immunogenicity of the RTS,S/AS01 malaria vaccine and implications for duration of vaccine efficacy: secondary analysis of data from a phase 3 randomised controlled trial. Lancet Infect. Dis. 15, 1450-1458. doi: 10.1016/S1473-3099(15)00239-X

Wilson, N. O., Jain, V., Roberts, C. E., Lucchi, N., Joel, P. K., Singh, M. P., et al. (2011). CXCL4 and CXCL10 predict risk of fatal cerebral malaria. Dis. Markers 30, 39-49. doi: 10.1155/2011/828256

Wu, X., Gowda, N. M., and Gowda, D. C. (2015). Phagosomal acidification prevents macrophage inflammatory cytokine production to malaria, and dendritic cells are the major source at the early stages of infection: implication for malaria protective immunity development. J. Biol. Chem. 290, 23135-23147. doi: 10.1074/jbc.M115.671065

Yanez, D. M., Manning, D. D., Cooley, A. J., Weidanz, W. P., and Van Der Heyde, H. C. (1996). Participation of lymphocyte subpopulations in the pathogenesis of experimental murine cerebral malaria. J. Immunol. 157, 1620-1624. 
Yao, Y., and Tsirka, S. E. (2011). Truncation of monocyte chemoattractant protein 1 by plasmin promotes blood-brain barrier disruption. J. Cell Sci. 124, 1486-1495. doi: $10.1242 /$ jcs. 082834

Zhu, J., Krishnegowda, G., Li, G., and Gowda, D. C. (2011). Proinflammatory responses by glycosylphosphatidylinositols (GPIs) of Plasmodium falciparum are mainly mediated through the recognition of TLR2/TLR1. Exp. Parasitol. 128, 205-211. doi: 10.1016/j.exppara.2011.03.010

Zhu, J., Wu, X., Goel, S., Gowda, N. M., Kumar, S., Krishnegowda, G., et al. (2009). MAPK-activated protein kinase 2 differentially regulates plasmodium falciparum glycosylphosphatidylinositol-induced production of tumor necrosis factor-\{alpha\} and interleukin-12 in macrophages. J. Biol. Chem. 284, 15750-15761. doi: 10.1074/jbc.M9011 11200
Zlotnik, A., and Yoshie, O. (2012). The chemokine superfamily revisited. Immunity 36, 705-716. doi: 10.1016/j.immuni.2012.05.008

Conflict of Interest Statement: The authors declare that the research was conducted in the absence of any commercial or financial relationships that could be construed as a potential conflict of interest.

Copyright (c) 2017 Dunst, Kamena and Matuschewski. This is an open-access article distributed under the terms of the Creative Commons Attribution License (CC BY). The use, distribution or reproduction in other forums is permitted, provided the original author(s) or licensor are credited and that the original publication in this journal is cited, in accordance with accepted academic practice. No use, distribution or reproduction is permitted which does not comply with these terms. 